\title{
A regional tidal/subtidal circulation model of the southeastern Bering Sea: Development, sensitivity analyses and hindcasting
}

\author{
Albert J. Hermann ${ }^{1 *}$, Phyllis J. Stabeno ${ }^{2}$, Dale B. Haidvogel ${ }^{3}$ and David L. Musgrave ${ }^{4}$ \\ 1 Joint Institute for the Study of the Atmosphere and the Ocean, Box 357941, University of \\ Washington, Seattle, WA 98195, hermann@pmel.noaa.gov \\ 2 Pacific Marine Environmental Laboratory, 7600 Sand Point Way, Seattle, WA 98115, \\ stabeno@pmel.noaa.gov \\ 3 Institute of Marine and Coastal Sciences, Rutgers University ,71 Dudley Road, New \\ Brunswick, New Jersey 08901, dale@ imcs.rutgers.edu \\ 4 University of Alaska Fairbanks, PO Box 757220, 129 O'Neill Bldg, Fairbanks, AK \\ 99775-7220,musgrave@ims.uaf.edu
}

For submission to: Topical Studies in Oceanography

November 2001

* Corresponding Author address:

Albert J. Hermann, NOAA/Pacific Marine Environmental Laboratory 7600 Sand Point Way NE, Seattle, WA 98115-0070, U.S.A.

Phone: 206-526-6495; Fax: 206-526-6485

hermann@pmel.noaa.gov

Contribution No. 2299 from NOAA/Pacific Marine Environmental Laboratory

This publication was supported by the Joint Institute for the Study of the Atmosphere and Ocean (JISAO) under NOAA Cooperative Agreement \#NA67RJO155, Contribution \#806. 


\section{ABSTRACT}

A regional eddy-resolving primitive equation circulation model was used to simulate circulation on the southeastern Bering Sea (SEBS) shelf and basin. This model resolves the dominant observed mean currents, eddies and meanders in the region, and simultaneously includes both tidal and subtidal dynamics. Circulation, temperature and salinity fields for years 1995 and 1997 were hindcast, using daily wind and buoyancy flux estimates, and tidal forcing derived from a global model. This paper describes the development of the regional model, a comparison of model results with available Eulerian and Lagrangian data, a comparison of results between the two hindcast years, and a sensitivity analysis. Based on these hindcasts and sensitivity analyses, we suggest the following: 1) The Bering Slope Current (BSC) is a primary source of large ( 100 $\mathrm{km}$ diameter) eddies in the SEBS basin. Smaller meanders are also formed along the $100 \mathrm{~m}$ isobath on the southeastern shelf, and along the $200 \mathrm{~m}$ isobath near the shelf break. 2) There is substantial interannual variability in the statistics of eddies within the basin, driven by variability in the strength of the ANSC. 3) The mean flow on the shelf is not strongly sensitive to changes in the imposed strength of the ANSC; rather, it is strongly sensitive to the local wind forcing. 4) Vertical mixing in the SEBS is strongly affected by both tidal and subtidal dynamics. Strongest mixing in the SEBS may in fact occur between the 100 and $400 \mathrm{~m}$ isobaths, near the Pribilof Islands, and in Unimak Pass.

Keywords: Coastal Oceanography, Dynamical Oceanography, Physical Oceanography, Fishery Oceanography, USA, Alaska, Bering Sea, $52^{\circ} \mathrm{N}-59^{\circ} \mathrm{N}, 174^{\circ} \mathrm{W}-163^{\circ} \mathrm{W}$. 


\section{INTRODUCTION}

\section{Physical Modeling in the Context of SEBSCC}

The southeast Bering Sea (SEBS) contains one of the most productive ecosystems on earth. Here a broad shelf supports high levels of primary production and a vigorous food chain which includes large populations of groundfish, mammals, and seabirds. Recent broad-scale changes in the physical and biological character of this area have occurred (Vance et al., 1998; Hunt et al, this volume). The Southeast Bering Sea Carrying Capacity program (SEBSCC) investigates physical and biological phenomena pertinent to the productivity of this rich southeastern Bering Sea ecosystem, with special emphasis on the role of juvenile walleye pollock (Theragra chalcogramma).

Knowledge of the temperature, salinity and velocity fields is crucial for understanding of the Bering Sea ecosystem. Primary production in the Bering Sea, as elsewhere, depends on the interplay of predation, light, advection, stratification, nutrient supply and vertical mixing, and varies widely in space and time (Springer and McRoy, 1996). While cross-shelf flux and weak vertical mixing of nutrients into the photic zone can replenish nutrients, excessive vertical mixing such as occurs during spring can deprive phytoplankton of adequate light. Secondary production is in turn strongly dependent on the magnitude and timing of this primary production. An early spring bloom with low levels of zooplankton will largely supply the benthos, while a 
later bloom will support a pelagic food web. Species at higher trophic levels, such as pollock, can be strongly affected by the circulation field as spawned individuals are advected to food-rich or food-poor environments. Hydrographic features may act to segregate predators from their prey (e.g. adult pollock from juveniles) (Wyllie-Echeveria, 1995).

Physical modeling studies are used within SEBSCC to project and diagnose the effects of climate change on Bering Sea circulation, to generate velocity and scalar (temperature, salinity) fields as a complement to biological field investigations, and ultimately to drive spatially explicit biological models of the Bering Sea ecosystem. Here, we report on the development of a primitive equation circulation model of the SEBS shelf and basin which includes both tidal and subtidal dynamics. We are using these physical simulations to explore the relative impact of winds, tides and heat flux in different years, and to investigate how these differences affect the fate of walleye pollock (Theragra chalcogramma) spawned in different regions of the SEBS. We begin with a description of some of the major circulation features of the Bering Sea, the appropriate physical models needed to simulate that circulation, a comparison of model results with available Eulerian and Lagrangian data, and a sensitivity analysis. In addition to model-data comparisons, we examine several scientific issues as follows:

1) Where are the primary sites for eddy formation in the SEBS?

2) Is there substantial interannual variability in the statistics of eddies in the region?

3) Does mean flow on the shelf and slope respond significantly to changes in the strength of the Aleutian North Slope Current? 
4) How does mixing on the Bering Sea shelf and slope vary spatially?

Major Physical Features of the Bering Sea

A description of current systems in the Bering Sea can be found in Stabeno et al. (1999).

Basically, inflow occurs through Aleutian Passes, predominantly Unimak, Amukta, Amchitka Passes and Near Strait. The principle outflow is Kamchatka Strait. While Bering Strait transports very little water $\left(\sim 0.8 \mathrm{~Sv}\right.$; Roach et al., 1995) $\left(1 \mathrm{~Sv}=10^{6} \mathrm{~m}^{3} \mathrm{~s}^{-1}\right)$, the flow from Bering to the Arctic determines flow patterns of the northern Bering Sea shelf. An overview of major currents in the region is illustrated in Fig. 1. Some primary physical features of the SEBS are as follows.

1. Principal Currents. The principal currents in the eastern Bering Sea basin are the Aleutian North Slope Current (ANSC) (Stabeno and Reed, 1994; Stabeno et al., 1999) and the Bering Slope Current (BSC; Schumacher and Reed, 1992). The ANSC flows along the northern side of the Aleutian Islands. The source of these waters is predominately Amchitka Pass and to a lesser extent Amukta Pass and Near Strait. The ANSC is the source of the BSC, which is the eastern boundary current of the cyclonic circulation of the Bering Sea basin (Stabeno and Reed, 1994).

2. Tidal influence. The southeastern Bering Sea (SEBS) is strongly influenced by tidal mixing, as well as wind- and buoyancy-driven subtidal flows. Subtidal flows interact with tides through 
their shared dependence on the density field; for example, fronts generated through tidal mixing on submarine banks generate subtidal flows along the front. The strong intensity of tidal and wind mixing, coupled with stratification by solar heating, leads to three biophysical domains on the shelf (Coachman 1986; Coachman 1982; Schumacher and Stabeno, 1998). The inner domain (0-50m depth) is well mixed or weakly stratified. The middle domain $(50-100 \mathrm{~m})$ is characterized by a two-layer system. The outer domain $(>100 \mathrm{~m})$, more oceanic in character, exhibits uniform density in top and bottom layers with a gradient layer in between.

3. Shelf-slope exchange. Exchange between shelf and slope waters provides nutrients to maintain high production on the shelf (Coachman, 1986), but the magnitude of this exchange is not well measured. Flow onto the shelf is a combination of currents interacting with topography (e.g. canyons) and instabilities of shelf break flows (Stabeno and Van Meurs, 2000).

4. Meanders and eddies. Meanders and eddies are common over the southeast corner of the basin (Schumacher and Stabeno, 1994). Altimetric, SST and drifter data have revealed mesoscale features on scales from 20-200 km (Stabeno et al., in prep).

5. Ice physics and the cold pool. Each year ice is formed in the polynyas to the lee of islands and the coast in the northern Bering Sea. This sea ice is advected south into the SEBS, where the leading edge melts. This exerts a profound effect on the heat and salt content of the shelf waters, density stratification and vertical mixing. A persistent pool of cold water $\left(<2{ }^{\circ} \mathrm{C}\right)$ is formed on the shelf in some years due to the influence of ice in the winter and spring. Fresh water input 
from melting ice frequently plays an important role in the setup of the 2-layer system in spring (Stabeno et al., 2001).

\section{$\underline{\text { Required model physics }}$}

While past modeling efforts have addressed some of the major circulation features, no single model has captured all of the regional physics relevant to the southeastern Bering Sea ecosystem. Past efforts include both large-scale models that encompass the Bering Sea (e.g. Semtner and Chervin, 1992), and regional models focused on the Bering Sea basin (e.g. Overland et al., 1994). The latter model excludes the shelf region, and hence cross-shelf flux. Several models have focused on the northern portion of the Bering Sea, in conjunction with the Chukchi Sea and Bering Strait (e.g. Overland and Roach, 1987; Spaulding et al., 1987; Shuert and Walsh, 1992; Nihoul et al., 1993). A suite of tidal models were developed as part of the OCSEAP program (e.g. Liu and Leendertse,1990), which included the southeastern shelf area. Walsh and McRoy (1986) employed a simple linear, wind-driven, free surface barotropic model of circulation on the southeastern shelf with $20 \mathrm{~km}$ grid spacing for Lagrangian studies of pollock advection, as part of the PROBES program. More recently, Wepestad et al. (2000) used an empirical model (OSCURS) to hindcast ocean surface drift in the SEBS, as part of an analysis of interannual variability in pollock stocks. A few models have focused specifically on the issue of ice dynamics in the Bering Sea. Overland and Pease (1988) developed a two-dimensional, barotropic, coupled sea-ice model on the Bering Sea shelf. Kantha and Mellor (1989) developed a two-dimensional (horizontal and depth) coupled ice-ocean model of the Bering Sea Marginal 
Ice Zone, with second moment closure for turbulent mixing in the water column.

Our goal here is to achieve eddy-resolving capability for the southeastern shelf, and the capability to predict or diagnose cross-shelf flows in that region, given the major features of the circulation. In general we cannot hope to replicate all the details of the circulation at any particular time, but can reasonably expect to capture the mean features and to replicate the statistics of the circulation field. Such goals have been accomplished in the North Pacific with an eddy-resolving primitive equation model (Hermann and Stabeno, 1996; Stabeno and Hermann, 1996).

Necessary elements for our purposes include sufficiently small horizontal grid spacing to resolve mesoscale eddies of 20-200 km scale that occur in the basin, the complex current patterns around the Pribilof Islands, and inflows and outflows through passes. Vertical resolution must be sufficient to allow decoupling of the flows from topography under stratified conditions, to permit the development of appropriate shears when the flow is baroclinically unstable, and to at least partially resolve boundary layers at the top and bottom of the water column, which meet in the shallow regions. Ice must ultimately be included, or at a minimum parameterized as surface buoyancy forcing, to generate the cold pool and freshen the water by ice melt in appropriate years.

Tidal energy must be present explicitly (as tidal currents) or implicitly through its effect on the pattern of vertical mixing. Traditionally, coastal models have been either tidal or subtidal, but 
rarely have both dynamics been captured in the same simulation. One significant obstacle to the development of such combined models has been the difficulty of constructing boundary conditions which simultaneously allow the specification of tidal information, the specification of subtidal information, and the free radiation of subtidal motions generated within the regional model domain.

\section{METHODS}

$\underline{\text { Governing equations and bathymetry }}$

To achieve an eddy-resolving, subtidal and tidal modeling capability for the SEBS, we utilized the free-surface, primitive equation, S-Coordinate Rutgers University Model (Song and Haidvogel, 1994), implemented at $4 \mathrm{~km}$ horizontal resolution (but telescoped as described below) with 20 vertical levels. This free surface, primitive equation model uses curvilinearorthogonal coordinates in the horizontal, while the stretched, bottom-following "s-coordinate" allows for flexible spacing of vertical grid points. The latter feature is especially useful in resolving boundary layers at the top of the water column (important for wind mixing) and near the bottom (important for tidal mixing). We implemented the model on a rectilinear telescoped grid using a stereographic projection, oriented at $45^{\circ}$ to true north and centered on $59 \mathrm{~N}, 173 \mathrm{~W}$. SCRUM is written in highly vectorized computer code, and the simulations reported here were obtained on vector architectures (CRAY J932) at the Arctic Region Supercomputing Center. 
A linearized version of the UNESCO equation of state was employed, with perturbation density computed by

$\rho^{\prime}=0.6394-0.1206 * \mathrm{~T}+0.7896 * \mathrm{~S}$

where $\rho, T$ and $\mathrm{S}$ are the perturbation density $\left(\mathrm{kg} \mathrm{m}^{-3}\right)$, temperature $\left({ }^{\circ} \mathrm{C}\right)$, and salinity (psu), respectively. Bathymetry was obtained from the 5-minute ETOPO5 global relief model, linearly interpolated to the model grid. The resulting bathymetry was truncated to lie between $50 \mathrm{~m}$ and $1000 \mathrm{~m}$, and smoothed with three passes of a Shapiro filter. The true bathymetry in this region is both deeper and shallower than the truncation limits; however both truncation and smoothing were required for numerical stability of the model. The S-coordinate feature of SCRUM allows more flexible placement of vertical gridpoints, than is the case in traditional sigma-coordinate models (where spacing is exactly proportional to the bottom depth). Vertical gridpoint spacing ranges from $1.8 \mathrm{~m}$ in the shallowest regions (50m depth) to $16 \mathrm{~m}$ in the deepest (1000m depth).

\section{$\underline{\text { Horizontal Boundary Conditions }}$}

External forcing of the regional model domain includes subtidal currents (derived from data) and the five most energetic tidal components for the Bering Sea (M2, S2, N2, K1, O1), with spatially dependent amplitude and phase derived from a global implementation of the Spectral Element Ocean Model. (SEOM; Haidvogel and Beckmann, 1999). 
SEOM has been developed for the purpose of high-resolution basin-scale modeling on unstructured global grids (Iskandarani et al., 1994). The resulting class of large-scale circulation models has several significant virtues over those using more traditional approaches, including complete geometric flexibility, regionally selective horizontal resolution, and the ability to avoid open boundary conditions by use of global grid refinement. The spectral element circulation model has now been applied in its reduced gravity form to a variety of test problems and global oceanic/atmospheric applications. When applied to a now-standard suite of shallow water test problems on the sphere, the SEOM model is shown to be highly competitive with other numerical models, including those based on spherical harmonic methods (Taylor et al., 1997). Oceanic applications on global, non-uniform grids show that these favorable properties are maintained in the presence of continental geometry and highly unstructured elemental meshes (Haidvogel et al., 1996).

It has been suggested that the phasing of the tides relative to one another in time can have important effects on the seasonal pattern of mixing, and should itself exhibit interannual variability. That is, in some years the interactions of the many tidal components will lead to especially large tidal velocities, and hence more mixing in particular months or even on specific days or times of day. This timing, and its interaction with short-lived wind mixing events, can have a dramatic impact on the ultimate stratification of the water column. To allow for these effects, we set the initial phase of each tidal component to properly correspond to its value at the start date of each hindcasted year, using software provided by H. Mofjeld (pers. comm.). 
For the regional model itself, we employed a telescoped grid with closed walls on all sides (Fig. 2); the finely resolved $(\mathrm{dx}=\mathrm{dy}=4 \mathrm{~km})$ area lies at the center of this telescoped grid. A similar telescoped approach (but without tides) has been used successfully in regional studies of circulation and biology in the northern Gulf of Alaska (Hermann and Stabeno, 1996). To accommodate both tidal and subtidal dynamics in the present model, we employ two spatially distinct nudging bands - that is, two separate areas where the regional model assimilates tidal versus subtidal information from the larger-scale model and/or data.

The nudging technique is described in detail Hermann et al (2001). An overview of this technique is as follows. Within the telescoped box, adjacent to the finely resolved area of interest, both currents and tracers are relaxed towards desired subtidal values, but not so strongly as to prevent the escape of (e.g. substantially reflect) any outgoing, internally generated mesoscale signals. The revised governing equation for a nudged variable $\mathrm{A}$ is:

$\mathrm{d} / \mathrm{dt}\{\mathrm{A}[\mathrm{x}, \mathrm{y}, \mathrm{x}, \mathrm{t}]\}=($ dynamical terms $)+\alpha[\mathrm{x}, \mathrm{y}] *\left(\mathrm{~A}_{\text {global }}-\mathrm{A}\right)$

Here $\mathrm{A}$ is the nudged variable, $\mathrm{A}_{\mathrm{global}}$ is the exterior value (e.g., from a global model or from data), "dynamical terms" represents all the model physics (advection, diffusion, acceleration, etc.) and $\alpha$ is the nudging constant. We note that such nudging is, in fact, a very primitive form of data assimilation, and that it has been used as a component in other open boundary condition techniques (e.g. Marchesiello et al., 2001; Palma and Matano, 1998). Note also that $\alpha$ varies in 
space, having nonzero values in specified bands and being set to zero elsewhere. In the present regional model, the nudged variables are as follows: $\mathrm{T}$ and $\mathrm{S}$ (three dimensional fields from monthly Levitus [1994] climatologies), depth-averaged U and V (from CTD-based total geostrophic transports), and free-surface height (two-dimensional fields from the global model tidal runs). The regional model treats the external (depth-averaged) mode as a separate variable, which greatly simplifies the nudging process. Although three-dimensional nudging of $\mathrm{U}$ and $\mathrm{V}$ is certainly possible, for simplicity we have used only two-dimensional information as a means of conveying tidal and subtidal information.

Tidal elevations (all five components) are assimilated in a tidal nudging band near the western and southern walls of the (telescoped) regional model domain (see Fig. 2). Temperature and salinity fields corresponding to desired subtidal inflows are assimilated along a subtidal nudging band further within the domain, but still external to the finely resolved SEBS. In each band nudging constants are linearly ramped in with weakest assimilation in effect at the inner edge, to minimize reflection and encourage absorption of internally generated signals. Subtidal barotropic velocities are also assimilated in small regions within the subtidal nudging band, to help set the value of specific boundary currents (here, the Alaskan Stream/ Alaska Coastal Current system entering from the east, and the Aleutian North Slope Current entering from the west).

Ideally the tidal signals assimilated in the outer domain will be transmitted through areas of subtidal nudging without attenuation. In practice this transmission will depend on the value of the subtidal nudging constants for scalars and velocity, the width of the subtidal nudging band, 
the frequencies of the tidal signals, and the phase speeds of the tidal signals. A scaling analysis (Hermann and Haidvogel, 2000; Hermann et al., 2001) suggests these criteria are satisfied for the SEBS model.

\section{$\underline{\text { Mixing }}$}

Vertical mixing in our model was computed using Mellor-Yamada level 2.0 closure (Mellor and Yamada, 1974). At its core, this method of closure is based on the local value of the Richardson

number. Background values of diffusivity for scalar and momentum were $10^{-4} \mathrm{~m}^{2} \mathrm{~s}^{-1}$ and $10^{-3} \mathrm{~m}^{2}$ $\mathrm{s}^{-1}$, respectively.

Horizontal mixing of momentum and scalars was computed using the biharmonic operator. Mixing coefficients were scaled by the local spacing of the (telescoped) grid in a manner which preserves the grid-equivalent Reynolds number at all locations. This method has been used successfully, and described in some detail, in Hermann and Stabeno (1996).

\section{$\underline{\text { Surface Forcing }}$}

Surface forcing was provided by daily average winds and heat fluxes for simulated years, obtained from the National Centers for Environmental Prediction/ National Center for Atmospheric Research (NCEP/NCAR) reanalysis project of NOAA (provided by the NOAA- 
CIRES Climate Diagnostics Center, Boulder, Colorado, USA, from their Web site at http://www.cdc.noaa.gov/). Such data is in good agreement with observations in the Bering Sea and North Pacific (Bond et al., 1994). Heat flux was computed as the sum of sensible heat flux, latent heat flux, longwave radiation, and shortwave radiation. We derived wind stress from the NCEP wind velocities using a simple quadratic relation, with (dimensionless) drag coefficient $\mathrm{Cd}=1.2 \times 10^{-3}$.

A substantial fraction of heat and buoyancy fluxes at the surface of the SEBS is due to ice melt. A full model of ice thermodynamics and advection was beyond the scope of this project. Instead, we developed a simple algorithm based on the observed phenomenon of ice being advected south into the SEBS and subsequently melting there (e.g. Stabeno et al., 2001). Weekly ice coverage was derived from ice pack data (at 1/4-degree resolution) from the U.S. National Ice Center, and also by digitizing maps of ice coverage from the U. S. National Weather Service to the same grid.

We treat ice as a forcing variable and compute daily ice melt based on the observed ice coverage, and the surface temperature computed in the circulation model relative to the temperature of the ice (assumed to be $-1.7^{\circ} \mathrm{C}$ ). Computed heat and buoyancy fluxes are added at the surface of the circulation model at each model time step in place of NCEP fluxes, based on the percentage of ice cover. Hence, with no ice present we are using the NCEP surface heat flux value, whereas with total ice coverage we are using the melt value based on the ice-water temperature difference: 


$$
\begin{aligned}
& B s=(1 .-F i) * B h+F i * R h^{*}(T s+1.7) \\
& S s=(-1 .) * F i * R m^{*}(T s+1.7)
\end{aligned}
$$

where $B s$ is the surface heat flux, $B h$ is the NCEP-derived surface heat flux, $S s$ is the surface salinity flux, $F i$ is the fractional ice coverage, $T s$ is the temperature at the surface of the ocean (that is, just below the ice layer), $R m$ is the rate of melting per degree $\mathrm{C}$ above freezing, and $R h$ is the rate of latent heat transfer per ${ }^{\circ} \mathrm{C}$ above freezing.

Melt rates were calibrated using temperature data from mid-shelf mooring site 2 (see Fig. 1;

Stabeno et al., 2001). The best fit to observations provided an estimate of $0.2 \mathrm{~m} \mathrm{~d}^{-1}$ of ice melted when the temperature is $1.35^{\circ} \mathrm{C}$ above $-1.7^{\circ} \mathrm{C}$ (that is, at $0.35^{\circ} \mathrm{C}$ ). For every cubic meter of ice melted we transfer $3.4 \times 10^{8} \mathrm{~J}$ of heat. Hence:

$$
\begin{aligned}
L h & =3.4 \times 10^{5} \mathrm{~J} \mathrm{~kg}^{-1} * 10^{3} \mathrm{~kg} \mathrm{~m}^{-3}=3.4 \times 10^{8} \mathrm{~J} \mathrm{~m}^{-3} \\
R m & =(0.2 / 86400) / 1.35 \mathrm{~m} \mathrm{~s}^{-1} \mathrm{C}^{-1} \\
R h & =-L h * R m
\end{aligned}
$$

Where $R h$ is in watts $\mathrm{m}^{-2}$ per ${ }^{\circ} \mathrm{C}$ of temperature difference.

Initialization, spinup, hindcasting, and sensitivity analysis 
The model was initialized using Levitus et al. (1994) climatological T and S for January, and driven with the daily winds, daily heat fluxes, and weekly ice values for specific years. Two recent years (1995 versus 1997) will be compared here, based on their radically different physical and biological character and the availability of field data. During both 1995 and 1997, extensive ice coverage occurred over the S.E. Bering Sea shelf. Sea surface temperatures in 1995 were normal with maximum values of $\sim 11{ }^{\circ} \mathrm{C}$. During 1997 remarkable conditions were observed; extremely weak winds persisted through summer, resulting in a shallow warm $\left(\sim 14^{\circ}\right.$ C) mixed layer. This is also the year that coccolithophores appeared for the first time in the SEBS, accompanied by an extensive die-off of seabirds (Hunt et al., this volume) and depletion of nutrients (Stockwell et al., 2001).

The ANSC barotropic inflow was given constant values of $3 \mathrm{~Sv}$ for the basic 1995 hindcast and 7 Sv for the basic 1997 hindcast, based on available hydrographic data spanning 1993-2001 (Stabeno and Reed, in prep). These values were derived from CTD lines perpendicular to the Aleutian Island chain (that is, southeast to northwest) at Unalaska Island, near the southwestern boundary of the finely resolved area of the model. Total geostrophic flow was calculated using a level of no motion at $1500 \mathrm{~m}$ or the local bathymetry, whichever was shallower. A sensitivity analysis was conducted, with $3 \mathrm{~Sv}$ vs. $7 \mathrm{~Sv}$ applied as forcing to each of the hindcasts, to assess the impact of this boundary condition on the interior flows. The Alaskan Stream barotropic flow was set as $10 \mathrm{~Sv}$, based on historical CTD data summarized by Reed (1984). 
In each yearly hindcast, the model was spun up for 90 days from a state of rest at Jan 15 . By the end of this spinup period, the circulation fields driven by lateral and surface forcing have filled out the model domain, and assumed statistically stationary values within the finely resolved area. Average velocities were subsequently stored on a daily basis. Comparisons of several lowpass filters revealed that this simple 24-hour average was effective at extracting the subtidal signal, even at a mid-shelf location where tidal KE was 95 percent of the total KE.

\section{RESULTS and DISCUSSION}

We will focus here on results in the following areas: 1) depth-integrated subtidal flows over bathymetry; 2) paths of pseudo-Lagrangian (constant depth) drifters; 3 ) temperature and velocity time series at two locations; 4) cross-shelf structure of the temperature field. Direct field data were available for model-data comparisons in each of these categories. Finally, we present computed fields of scalar diffusivity (for which no corresponding data are available). Correspondence of the tidal component of model output to observed tidal fields will be reported in a separate communication.

Depth-integrated subtidal flow over bathymetry.

Plots of depth-averaged subtidal flow for 1995 and 1997 on Day of Year (DOY) 133 and 195 (May 13 and July 14, respectively) (figures 3-6) reveal many of the major features in the SEBS 
(note: DOY $0=$ Jan $100 \mathrm{GMT}$ ). In particular, we observe a sluggish circulation on the middle shelf, stronger northwestward flow along the 100 meter isobath, a vigorous northwestward alongshelf flow in the basin and near the shelf-break, and anticyclonic flows around the Pribilof Islands. Meanders with scales of 25-50 km appear on the shelf, especially near the $100 \mathrm{~m}$ isobath and near the shelf break (200 $\mathrm{m}$ isobath).

The clockwise flow around the Pribilof Islands is similar to that observed in Kowalik and Stabeno (1999), and are associated with tidal residuals in purely tidal simulations. The eastward cross-shelf flow originating near the Pribilof Islands (Reed and Stabeno, 1996; Reed, 1998) is not adequately captured by these model runs.

A well-defined flow in the vicinity of Unimak Pass is similar to observations, with a portion flowing along the Alaska Peninsula and the remainder combining with flow up Bering Canyon and turning northwestward along the $100 \mathrm{~m}$ isobath (Stabeno et al., this volume).

Strong mesoscale eddy activity (typically $50-100 \mathrm{~km}$ diameter) is produced in the basin, with free surface height signatures $(\sim 5 \mathrm{~cm}$, not shown) very similar to those observed in altimeter data (Stabeno et al., in prep). The BSC, while present, appears further off the shelf break than has typically been observed (Stabeno et al., in prep), although recently collected CTD data (R. Reed, pers. comm.) support the existence of this path during some periods. Animations of sea-surface height (not shown) indicate eddies forming in the ANSC/BSC of the model domain and sweeping to the northwest along the shelf break. 
Simulations for 1995 versus 1997 exhibit marked differences in velocity fields for the deep basin (compare Figs. 3 and 5). The mesoscale eddy activity is much greater in 1997 than 1995. A Hovmuller diagram of depth-integrated alongshelf velocity as a function of cross-basin distance and time for each year (Fig. 7; cross-shelf distance location shown as in Figs. 3-6) highlights the different location of the BSC in the two years, and the greater number of eddies in 1997 relative to 1995. In 1995, the BSC (defined here as the core of maximum depth-integrated alongshelf velocity) is centered at $\sim 150 \mathrm{~km}$ offshore of the shelf break, whereas in 1997 it is centered $\sim 100$ $\mathrm{km}$ offshore of the shelf break.

Maps of Eddy Kinetic Energy (EKE) were also calculated for the deep basin using the lowpassed barotropic velocities produced by the model (Fig. 8). First, the time-mean barotropic velocity was removed at each model gridpoint; the perturbation fields were then bandpass filtered in space to extract features $<160 \mathrm{~km}$ in length. The variance of the resulting time series was used as our measure of EKE at each horizontal location. Note how largest values are obtained in the interior of the model, and along the mean path of the BSC (compare Figs. 7 and 8). Indeed, it appears the internal dynamics of our model are capable of generating observed eddy variability from the ANSC/BSC system alone, without the benefit of eddies advected in from the deeper basin. In 1997, observed transport in an eddy was found to match observed transport of the BSC (unpublished data). These observations and the model results together suggest the BSC, in particular, as a prime source of $100 \mathrm{~km}$ - scale eddies observed in the SEBS. 
A comparison of EKE maps for 1995 vs. 1997 (Fig. 8) illustrates uniformly higher values for 1997. As in Fig. 7, these results suggest a substantial interannual variability in the statistics of eddies in the region. Much of the interannual variability appears due to the stronger ANSC supplied as a boundary condition for 1997, which provided more mean kinetic energy to the basin and shelf break. In sensitivity experiments where this boundary condition was varied, the larger ( $7 \mathrm{~Sv}$ ) value led to more energetic eddies in the basin, and penetration of the BSC close to the shelf break, irrespective of the (1995/1997) surface forcing. Local winds in our regional model, by themselves, are not capable of spinning up a strong ANSC. Conversely, flows on the shelf appear relatively unaffected by the strength of the ANSC inflow; instead, they are highly sensitive to the surface forcing specific to each year. For example, when $3 \mathrm{~Sv}$ was specified for the ANSC in sensitivity tests of the 1997 hindcast, the calculated barotropic velocities at mooring sites 2 and 3 (see Fig. 1) were, in fact, indistinguishable (differences less than $10^{-3} \mathrm{~m} \mathrm{~s}^{-}$ $\left.{ }^{1}\right)$ from results obtained with a $7 \mathrm{~Sv}$ ANSC.

\section{$\underline{\text { Drifter tracks }}$}

As a further check on the velocities produced by the model, we compared the tracks of observed drifters in 1997 with floats released at corresponding locations and times in the model (Fig. 9). The true drifters are drogued at 40m, and the numerical floats are tracked using pre-stored, lowpass-filtered velocities at $40 \mathrm{~m}$ depth from the model. Float release locations are noted in Figs. 5 and 6. We observed a striking correspondence in several cases of this "paired release", and wide divergence in others: 
1) Shelf break. A paired release at the shelf break near the Aleutians on DOY 135 indicates northwestward flow along the shelf break for the data, and eventual drift onto the SEBS shelf for the model (Fig. 9a). Model velocities at the time of release (Fig. 5) indicate the modeled ANSC passing just northwest of the release point (and hence failing to advect the modeled float along the path observed in the data).

2) Deep basin. A paired release in the deep basin near Pribilof canyon on DOY 135 reveals offshore drift and anticyclonic loops for both model and data (Fig. 9b). The drifter had been deployed in an eddy which translated slowly to the southwest; a corresponding model eddy followed a similar path (see Fig. 5).

3) Outer shelf. A paired release on the outer shelf just north of the Pribilof Islands on DOY 195 indicates northwestward flow of similar extent in model and data (Fig. 9c). A release on the shelf near Unimak Pass illustrates similar mean speed and direction along the $100 \mathrm{~m}$ isobath in both model and data (Fig. 9d). The northern release, in particular, appears to be in a region of lower shear than releases on the outer shelf and basin (compare Figs. 5 and 6), leading to a closer correspondence between model and data.

It is important to note that release and tracking of the numerical floats at $5 \mathrm{~m}$ yielded significantly different paths and endpoints than the $40 \mathrm{~m}$ case. This reflects both the greater influence of daily wind fluctuations on the near-surface velocities, and the rotation of the 
currents with depth (see Fig. 10). This divergence of results between 5 and $40 \mathrm{~m}$ can obviously have significant biological impacts; Ekman drift at the surface may, in fact, be a simple route for transport of biological materials from the deep basin onto the shallow shelf. This issue, and a comparison of our results with those from an empirical model of surface currents in the SEBS (Wepestad et al., 2000) will be addressed in a separate communication.

Temperature and velocity time series at moorings

We have compared depth-time profiles of temperature and subtidal velocity from the model with equivalent profiles from Miniature Temperature Recorders and current meters at two locations near $60 \mathrm{~m}$ and $120 \mathrm{~m}$ isobaths, respectively (mooring stations S2 and S3, noted in Figure 1. ;see Stabeno et al., 1998, for details). Results are shown in Figures 10-13. Relevant features include the following:

1) Similar temperature features appear at the beginning of the year in both model and data. In particular note a cooling event in early April, 1997 (Fig. 11), which was reproduced by the hindcast (Fig. 10).

2) The modeled water column begins to stratify earlier, and heats up more in the spring and summer, than is observed in the data. At the same time, the modeled summer stratification is weaker than indicated by the data. These results appear due to excessive diffusion of heat down 
from the surface, and possibly an overestimate of surface heat flux from the NCEP data. At least part of this discrepancy may be due to the prevalence of fog on the SEBS shelf, as the NCEP reanalysis may not always properly include fog effects in heat flux estimates.

3) There is a similar breakdown of the stratified water column at the end of summer in both model and data. This breakdown occurs sooner in the model, probably due to its weaker stratification relative to the data.

4) The modeled deep flow at mooring site 3 exhibits less variance than its counterpart at site 2 . Generally, the flow at site 2 (in both model and data) is highly variable and has a very weak time-mean. The steady deep flow at location 3 is indicative of the (modeled and measured) flow along the 100-m isobath.

5) In both data and model, a warmer water column is observed in 1997 than in 1995, and colder spring temperatures at site 2 than at site 3 .

\section{Temperature cross-shelf structure}

The cross-shelf structure of the modeled temperature field in 1997 (Fig. 14) indicates a cold pool with similar offshore extent, but slightly warmer temperatures, than were observed in data (Fig. 15). In both model and data, strong stratification of the water column is observed at $\sim 10-20 \mathrm{~m}$ depth across the shelf, with weaker (and shallower) stratification in the shallowest areas. A 
comparison of model results for 1995 and 1997 (Fig. 14) highlights the greater volume of the cold pool in 1995, in conformance with the time series results (Figs. 10-13). Both of the model hindcasts produce a secondary, smaller cold pool at the edge of the shelf $(\sim 140 \mathrm{~m})$. Such features have been observed in data, and attributed to an on-shelf pulse of slope water. In the model simulations, the likely source of the secondary cold pool appears to be alongshelf advection.

\section{Spatial pattern of mixing}

In significant portions of the SEBS the tidal velocities account for greater than $95 \%$ of the Total Kinetic Energy in current meter records (Coachman, 1986; Schumacher and Stabeno, 1998). One might expect that vertical mixing would be uniformly strong in regions of high tidal energy and weaker elsewhere. However, a rendering of maximum vertical diffusivity (instantaneous value on DOY 195, 1997), computed from the model (Fig. 16), suggests a more complex pattern. While values were higher on the shelf than in the basin, highest values were produced between the $100-140 \mathrm{~m}$ isobaths (where persistent subtidal flows $\sim 10 \mathrm{~m} \mathrm{~s}^{-1}$ were generated), around the Pribilof Islands (where tidal residuals are strong), and in Unimak Pass. An examination of the vertical structure (not shown) reveals the maximum values were usually (but not always) attained near the seafloor. These results suggest that both subtidal and tidal dynamics contribute strongly to the overall mixing pattern.

\section{CONCLUSIONS and FUTURE WORK}


Our regional model of the SEBS appears to allow a proper interaction between tidal mixing and subtidal currents set by the density field. These interactions play a significant role in both physical and biological dynamics, and permit a more realistic assessment of interannual variability in the SEBS. Major circulation features and observed hydrography of the region have been reproduced, and our simulations yield many results (both Eulerian and Lagrangian) consistent with specific observed features in different years. Based on our hindcasts and sensitivity analyses thus far, we suggest the following:

1) The BSC is a significant generator of $100 \mathrm{~km}$ - scale eddies in the deep basin of the SEBS; internal dynamics (as opposed to advection of features from beyond the SEBS) appear capable of generating observed SSH variability in this region. Smaller meanders are also formed along the $100 \mathrm{~m}$ isobath on the southeastern shelf, and along the $200 \mathrm{~m}$ isobath near the shelf break.

2) There is substantial interannual variability in the statistics of eddies within the basin, apparently driven by variability in the strength of the ANSC/BSC system.

3) The mean flow on the shelf does not appear sensitive to changes in the imposed strength of the ANSC; rather, it appears sensitive only to the local wind forcing. 
4) Vertical mixing in the SEBS may be strongest between the 100-140 m isobaths, at Unimak Pass, and near the Pribilof Islands. Apparently, it is strongly affected by both tidal and subtidal flows.

Anticipated improvements in the model include a refinement of the vertical mixing scheme, to achieve better correspondence with observed stratification. Also, the extreme sensitivity of basin circulation to the strength of the imposed, depth-averaged ANSC underscores the need for either a larger model domain, or a more refined (e.g. depth- and time-varying) boundary condition on velocity derived from data or a larger (e.g. global) model. A refinement of atmospheric heating is critical, since vertically averaged temperatures are warmer in the model simulations than have been observed.

Future experiments with the model include an extended series of hindcasts for coupling to individual-based models of fish, and a more thorough analysis of Lagrangian paths and statistics from the model. These activities are of considerable interest to biological studies of the SEBS; in particular, cross-shelf nutrient and biomass transport (both near-surface and subsurface) remain key outstanding issues in the SEBS.

\section{$\underline{\text { Acknowledgments }}$}

This research is contribution 2299 from NOAA/ Pacific Marine Environmental Laboratory and contribution FOCI-S425 to NOAA's Fisheries Oceanography Coordinated Investigations, and 
was supported by the Joint Institute for the study of the Atmosphere and the Oceans under cooperative agreement NA67RJ0155, contribution \#806. SEBSCC is sponsored by the Coastal Ocean Program of NOAA. We thank Sigrid Salo for processing ice cover data, Elizabeth Dobbins for assistance with development of the float tracking program, and Dr. Hal Mofjeld for assistance with tidal phasing. Support from the Arctic Region Supercomputing Center is gratefully acknowledged. 


\section{FIGURE CAPTIONS}

Fig. 1 Place names and schematic of mean circulation in the southeastern Bering Sea. ANSC = Aleutian North Slope Current; BSC = Bering Slope Current. Positions of continuous hydrographic mooring sites 2 and 3, and a cross-shelf hydrographic section, are noted. Modified from Stabeno et al. (1999).

Fig. 2 Structure of the grid used by the circulation model, with bathymetry (contoured, m) and nudging bands. Land areas (Alaska and the Aleutian Islands) are indicated in black; the grid is rotated approximately $45^{\circ}$ from true north. The central box denotes the finely resolved domain with $4 \mathrm{~km}$ spacing. The grid is telescoped external to this area, with solid walls at the outer edge of the global domain. Stars indicate gridpoints where (fast) nudging of tidal free surface height is in effect; triangles indicate gridpoints where (slow) nudging of subtidal temperature and salinity is in effect. Small sections of the subtidal nudging band include nudging of barotropic velocity, to better assimilate the Alaskan Stream and Aleutian North Slope Current (see Fig. 1) at the boundary of the finely resolved domain.

Fig. 3. Subtidal (i.e. low-pass filtered) current vectors $\left(\mathrm{m} \mathrm{s}^{-1}\right)$ with bathymetry in the finely resolved domain (see Fig. 1) for DOY 133.5 (May 13), 1995. Model bathymetry is contoured (meters). Only every second vector is plotted in this figure; full grid spacing is $4 \mathrm{~km}$. Horizontal distances are indicated in meters. The Pribilof Islands appear as two black dots in upper half of 
the figure. Model grid is rotated 45 degrees (counterclockwise) from true North. Solid line indicates location of cross-section in Figure 7.

Fig. 4. Same as Fig. 3, for DOY 195.5 (July 14), 1995

Fig. 5. Same as Fig. 3, for DOY 133.5 (May 13), 1997

Fig. 6. Same as Fig. 3, for DOY 195.5 (July 14), 1997

Fig. 7. Hovmuller diagrams of depth-integrated alongshelf flow $\left(\mathrm{m}^{2} \mathrm{~s}^{-1}\right)$ at alongshelf distance $y$ $=-5.2 \times 10^{6} \mathrm{~m}$ (see Fig. 3), as a function of cross-basin distance $\left(\mathrm{x}=-3 \times 10^{6}\right.$ to $-.5 \times 10^{6} \mathrm{~m}$, as in Figs. 3-6) and time (DOY). The shelf break is located at the right-hand edge of the figure ( $\mathrm{x}=-$ $.5 \times 10^{6} \mathrm{~m}$ ). Results are shown for years 1995 (a) and 1997 (b).

Fig. 8. Spatial maps of time-averaged EKE $\left(\mathrm{m}^{2} \mathrm{~s}^{-2} * 10^{3}\right)$, for DOY 105-195 in years 1995 (a) and 1997 (b).

Fig. 9 Actual (thin lines) and simulated (large dots) drifter tracks. Upper left and lower left panels (a,b) represent floats released on DOY 135, 1997; upper right and lower right panels (c,d) represent floats released on DOY 195, 1997. Color indicates DOY (note different colorbars for DOY 135 and 195 tracks). 
Fig. 10. Time-depth series of modeled temperature $\left({ }^{\circ} \mathrm{C}\right)$ and velocity $\left(\mathrm{m} \mathrm{s}^{-1}\right.$; upward direction indicates northward flow) at mooring site 3 for years 1995 (a) and 1997 (b).

Fig. 11. Time-depth series of measured temperature at mooring site 3 for years 1995 (a) and 1997 (b).

Fig. 12. Time-depth series of modeled temperature at mooring site 2 for years 1995 (a) and 1997 (b).

Fig. 13. Time-depth series of measured temperature at mooring site 2 for years 1995 (a) and 1997 (b).

Fig. 14. Cross-shelf transect of modeled temperature $\left({ }^{\circ} \mathrm{C}\right)$ for mid-June for 1995 (a) and 1997 (b), with approximate locations noted for mooring sites 2 and 3 (see Fig. 1).

Figure 15. Cross-shelf transect of measured temperature $\left({ }^{\circ} \mathrm{C}\right)$ for mid-June (see Fig. 1 for location).

Fig. $16 \log _{10}$ of vertical mixing $\left(\mathrm{m}^{2} \mathrm{~s}^{-1}\right)$ on DOY 195 (July 14), 1997 as computed by the model. Shaded values represent the maximum value in the water column, as a function of horizontal location. Bathymetry is contoured $(\mathrm{m})$. 


\section{REFERENCES}

Bond, N. A., J. E. Overland, Turet, P., 1994. Spatial and temporal characteristics of the wind forcing of the Bering Sea. Journal of Climate 7, 1119-1130.

Coachman, L. K., 1986. Circulation, water masses and fluxes on the southeastern Bering Sea shelf. Continental Shelf Research 5, 23-108.

Coachman, L. K., 1982. Flow convergence over a broad, flat continental shelf. Continental Shelf Research 1, 1-14.

Haidvogel, D.B., Beckmann, A., 1999. Numerical Ocean Circulation Modeling. Imperial College Press, 318 pp.

Haidvogel, D.B., E. Curchitser, M. Iskandarani, R. Hughes, Taylor, M., 1996. Global modeling of the ocean and atmosphere using the spectral element method. In: Lin, C. A., Laprise, R., Ritchie, H. (eds.), Numerical methods in atmospheric and oceanic modelling: the Andre J. Robert memorial volume. pp. 505-531.

Hermann, A. J., Stabeno, P. J., 1996. An eddy resolving model of circulation on the western Gulf of Alaska shelf. I. Model development and sensitivity analyses. Journal of Geophysical Research 101, 1129-1149.

Hermann, A. J., Haidvogel, D. B., 2000. Simultaneous modeling of tidal and subtidal dynamics in the Bering Sea. Proceedings of the International conference on coastal ocean and semienclosed seas: circulation and ecology modeling and monitoring. Moscow Institute of Physics \& Technology, Moscow, Russia.

Hermann, A. J., D. B. Haidvogel, E. L. Dobbins, Stabeno, P. J., 2001. Coupling Global and Regional Circulation Models in the Coastal Gulf of Alaska. Prog. Oceanog., in press.

Hunt, G. L., Jr., P. Stabeno, G. Walters, E. Sinclair, R. D. Brodeur, J. M. Napp, Bond, N.A., 2001. The eastern Bering Sea: Three decades of change. This volume.

Iskandarani, M., D. B. Haidvogel, Boyd, J. P., 1995. A staggered spectral finite element model with application to the oceanic shallow water equations. International Journal of Numerical Methods in Fluids, 20, 393-414.

Kantha, L.H., Mellor, G. L., 1989. A two dimensional coupled ice-ocean model of the Bering Sea. Journal of Geophysical Research, 94, 10921-935. 
Kowalik, Z., Stabeno, P., 1999. Trapped motion around the Pribilof Island in the Bering Sea. Journal of Geophysical Research, 104, 25 667-25 684.

Liu, S.-K., Leendertse, J. J., 1990. Modeling the Alaskan Continental Shelf Waters. Final Report, Outer Continental Shelf Environmental Assessment Program (OCSEAP), Minerals Management Service, Vol. 70, 626 pp.

Levitus, S., et al. 1994. World Ocean Atlas 1994, 4 volumes, Washington, D.C., NOAA/NESDIS/NODC.

Mellor, G. L., Yamada, T., 1974. A hierarchy of turbulence closure models for planetary boundary layers. Journal of the Atmospheric Sciences, 31, 1791-1806.

Nihoul, J. C. J., Adam, P., Brasseur, P., Deleersnijder, E., Djenidi, S., Haus, J., 1993. Threedimensional general circulation model of the northern Bering Sea's ecohydrodynamics. Continental Shelf Research, 13, 509-542.

Overland, J. E., Roach, A., 1987. Northward flow in the Bering and Chukchi Seas, Journal of Geophysical Research, 92, 7097-7105.

Overland, J. E., Pease, C. H., 1988. Modeling ice dynamics of coastal seas, Journal of Geophysical Research, 93, 15619 - 15637.

Overland, J. E., M.C. Spillane, H.E. Hurlburt, Wallcraft, A. J., 1994. A numerical study of the circulation of the Bering Sea basin and exchange with the North Pacific Ocean. Journal of Physical Oceanography, 24, 736-758.

Reed, R. K., 1984. Flow of the Alaskan Stream and its variations. Deep Sea Res. 31(A):369-386.

Reed, R. K., 1998. Confirmation of a convoluted flow over the southeastern Bering Sea shelf. Continental Shelf Research, 18, 99-103.

Reed, R. K., Stabeno, P. J., 1996. On the climatological mean circulation over the eastern Bering Sea shelf. Continental Shelf Research, 16, 1297-1305.

Roach, A. T., Aagaard, K., Pease, C. H., Salo, S. A., Weingartner, T., Pavlov, V., Kulakov, M., 1995. Direct measurements of transport and water properties through the Bering Strait. Journal of Geophysical Research, 100, 18 443-18 457.

Schumacher, J. D., Reed, R. K., 1992. Characteristics of currents over the continental slope of the eastern Bering Sea. Journal of Geophysical Research, 97, 9423-9433.

Schumacher, J. D., Stabeno, P. J., 1994. Ubiquitous eddies of the eastern Bering Sea basin and their coincidence with concentrations of larval pollock. Fisheries Oceanography, 3, 182-190. 
Schumacher, J.D., Stabeno, P. J., 1998: The continental shelf of the Bering Sea. The Sea, Vol. VII, pp. 789-822.

Semtner, A. J., Jr., Chervin, R. M., 1992. Ocean general circulation from a global eddy-resolving model. Journal of Geophysical Research, 97, 5493-5550.

Shuert, P.G., Walsh, J. J., 1992. A time-dependent depth-integrated barotropic physical model of the Bering/Chukchi seas for use in ecosystem analysis. Journal of Marine Systems, 3(1-2),141161.

Spaulding, M., T. Isaji, D. Mendelsohn, Turner, A. C., 1987. Numerical simulation of winddriven flow through the Bering Strait. Journal of Physical Oceanography, 17, 1799-1816.

Springer, A. M., McRoy, C.P., Flint, M. V., 1996. The Bering Sea Greenbelt: Shelf-edge processes and ecosystem production. Fisheries Oceanography, 5 (3-4), 205-223.

Song, Y., Haidvogel, D. B., 1994. A semi-implicit ocean circulation model using a generalized topography-following coordinate system. Journal of Computational Physics, 115, 228-244.

Stabeno, P. J., Reed, R. K., 1994. Circulation in the Bering Sea observed by satellite-tracked drifters: 1986-1993. Journal of Physical Oceanography, 24, 848-854.

Stabeno, P. J., Hermann, A. J., 1996. An eddy resolving model of circulation in the western Gulf of Alaska II. Comparison of results to oceanographic observations. Journal of Geophysical Research, 101, 1151-1161.

Stabeno, P. J., Schumacher, J. D., Davis, R. F., Napp, J. M., 1998. Under-ice observations of water column temperature, salinity and spring phytoplankton dynamics: Eastern Bering Sea shelf. Jourmal of Marine Research, 56, 239-255.

Stabeno, P. J. , N. A. Bond, N. B. Kachel, S. A. Salo, Schumacher, J. D., 1999. On the temporal variability of the physical environment over the Southeastern Bering Sea. Fisheries Oceanography, in press.

Stabeno, P. J., N. A. Bond, N. K. Kachel, S. A. Salo, Schumacher, J. D., 2001. On the temporal variability of the physical environment over the southeastern Bering Sea. Fisheries Oceanography, in press.

Stabeno, P. J., R. K. Reed, Napp, J. M., 2001. Transport through Unimak Pass, Alaska. This volume.

Stabeno, P., van Meurs, P., 1999. Evidence for episodic on-shelf flow. Journal of Geophysical Research, 104, 29715 - 29720.

Stockwell, D. A., Whitledge. T. E., Zeeman, S. I., Coyle, K. O., Napp, J. M., Brodeur, R. D., 
Pinchuk, A. I., 2001. Anomalous conditions in the southeastern Bering Sea, 1997: Nutrients, phytoplankton, and zooplankton. Fisheries Oceanography (In press).

Taylor, M., J. Tribbia, Iskandarani, M., 1997. The spectral element method for the shallow water equations on the sphere. Journal of Computational Physics, 130(1), 92-108.

Vance, T. C., Baier, C., Brodeur, R. D., Coyle, K., Decker, M. B., Wyllie-Echeverria, T., Hunt, G., Napp, J. M., Schumacher, J. D., Stabeno, P. J., Stockwell, D., Tynan, C., Whitledge, T. E., Zeeman, S., 1998. Ecosystem Anomalies in the Eastern Bering Sea: Including Blooms, Birds and Other Biota. EOS, Transactions of the American Geophysical Union, 79(10), 121-126.

Walsh, J. J., McRoy, C. P., 1986. Ecosystem analysis in the southeastern Bering Sea. Continental Shelf Research, 5, 259-288.

Wepestad, V. G., L. W. Fritz, W. J. Ingraham, Megrey, B. A., 2000. On relationships between cannibalism, climate variability, physical transport and recruitment success of Bering Sea walleye pollock (Theragra chalcogramma). ICES Journal of Marine Science, 57, 272-278.

Wyllie-Echeveria, T., 1995. Seasonal ice, the cold pool and Gadid distribution on the Bering Sea shelf. Ph.D. Thesis, Univ. Alaska, Fairbanks, 281 pp. 


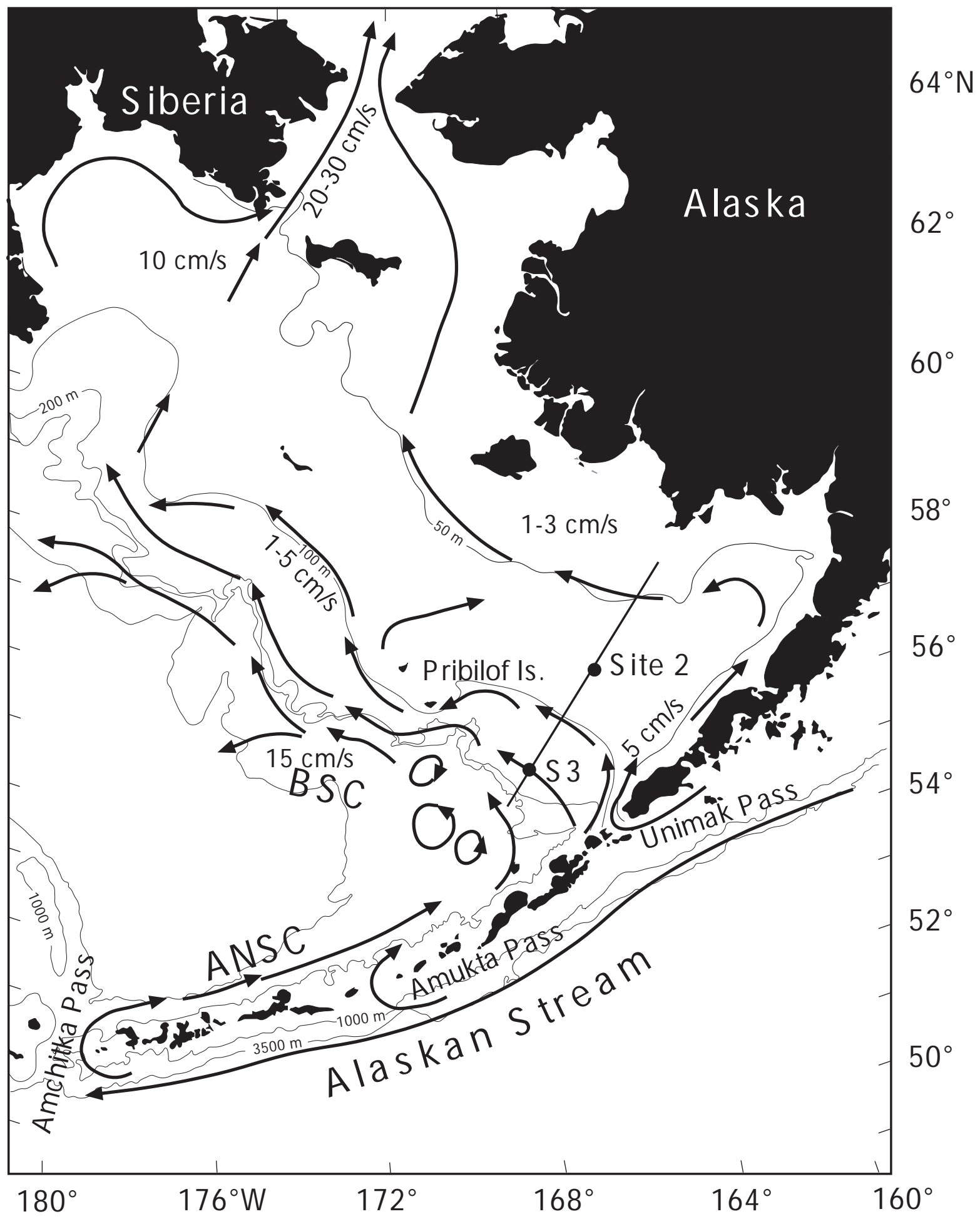

Fig. 1 Place names and schematic of mean circulation in the southeastern Bering Sea. ANSC = Aleutian North Slope Current; BSC = Bering Slope Current. Positions of continuous hydrographic mooring sites 2 and 3, and a cross-shelf hydrographic section, are noted. Modified from Stabeno et al. (1999). 


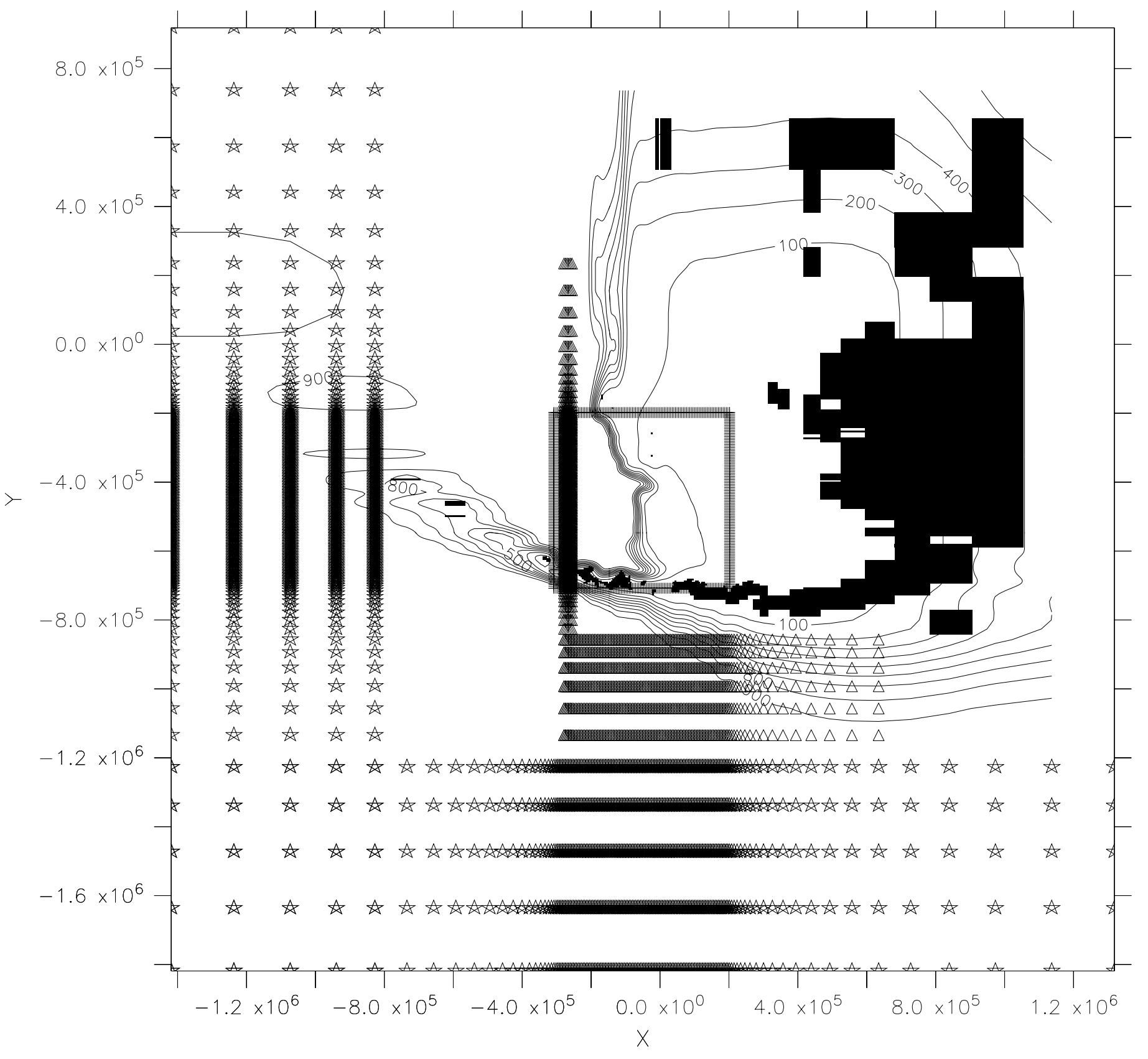

Fig. 2 Structure of the grid used by the circulation model, with bathymetry (contoured, $\mathrm{m}$ ) and nudging bands. Land areas (Alaska and the Aleutian Islands) are indicated in black; the grid is rotated approximately 45 ofrom true north. The central box denotes the finely resolved domain with $4 \mathrm{~km}$ spacing. The grid is telescoped external to this area, with solid walls at the outer edge of the global domain. Stars indicate gridpoints where (fast) nudging of tidal free surface height is in effect; triangles indicate gridpoints where (slow) nudging of subtidal temperature and salinity is in effect. Small sections of the subtidal nudging band include nudging of barotropic velocity, to better assimilate the Alaskan Stream and Aleutian North Slope Current (see Fig. 1) at the boundary of the finely resolved domain. 


\section{VELOCITY IN SEBS DAY 133.5 1995(3sv)}

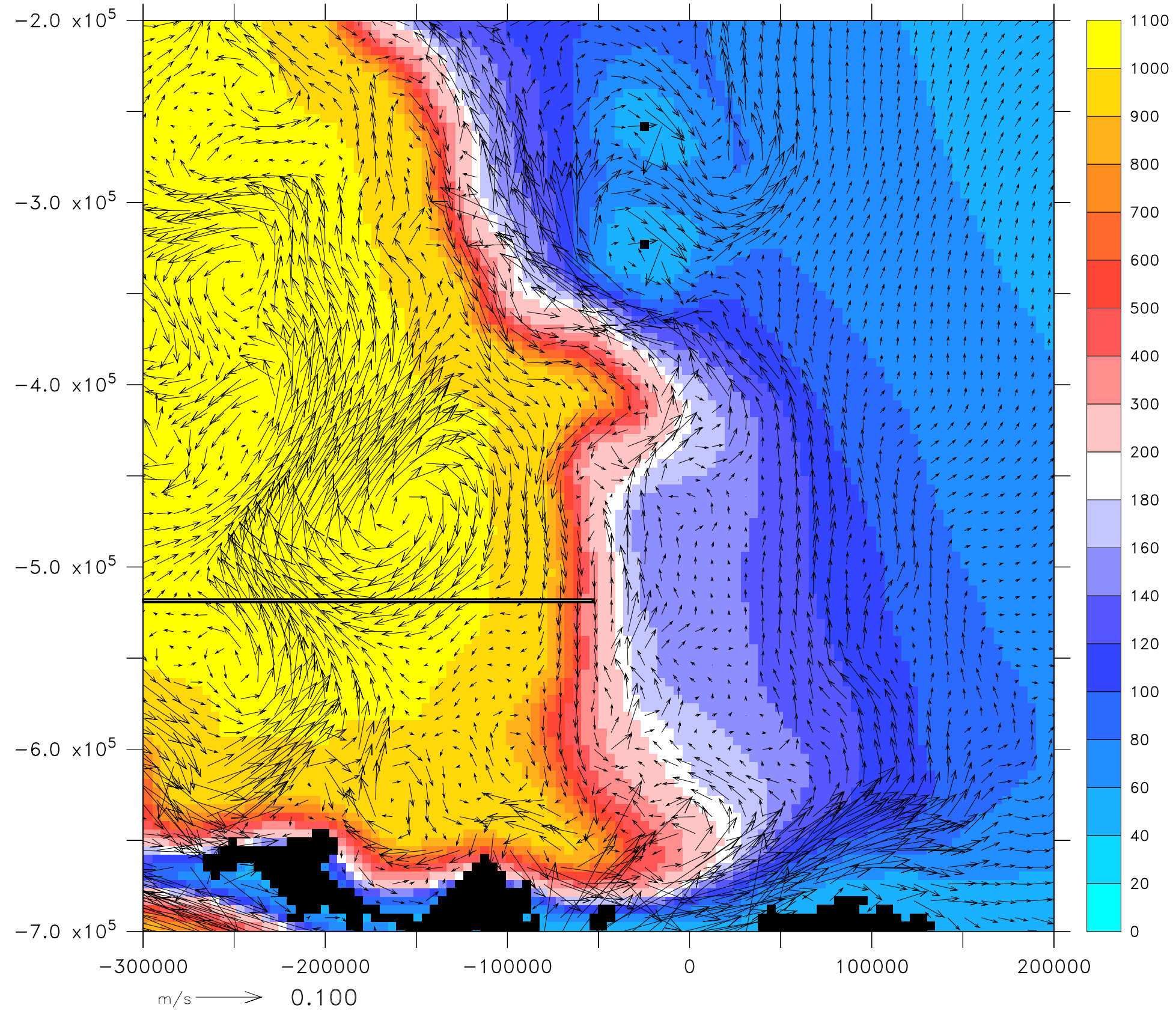

Fig. 3. Subtidal (i.e. low-pass filtered) current vectors (m s -1 ) with bathymetry in the finely resolved domain (see Fig. 1) for DOY 133.5 (May 13), 1995. Model bathymetry is contoured (meters). Only every second vector is plotted in this figure; full grid spacing is $4 \mathrm{~km}$. Horizontal distances are indicated in meters. The Pribilof Islands appear as two black dots in upper half of the figure. Model grid is rotated 45 degrees (counterclockwise) from true North. Solid line indicates location of cross-section in Figure 7. 


\section{VELOCITY IN SEBS DAY 195.51995 (3sv)}

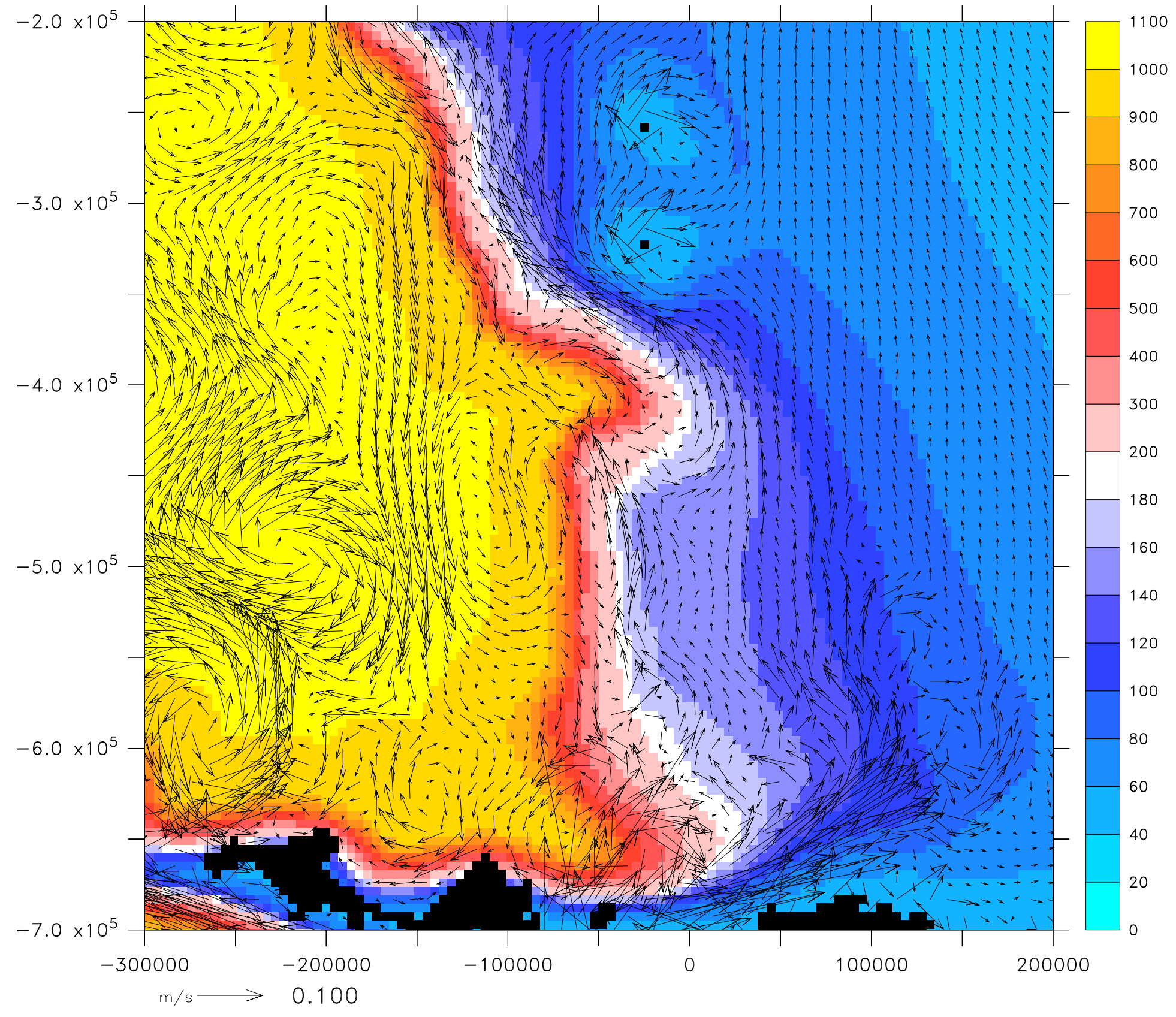

Fig. 4. Same as Fig. 3, for DOY 195.5 (July 14), 1995 


\section{VELOCITY IN SEBS DAY 133.5 1997(7sv)}

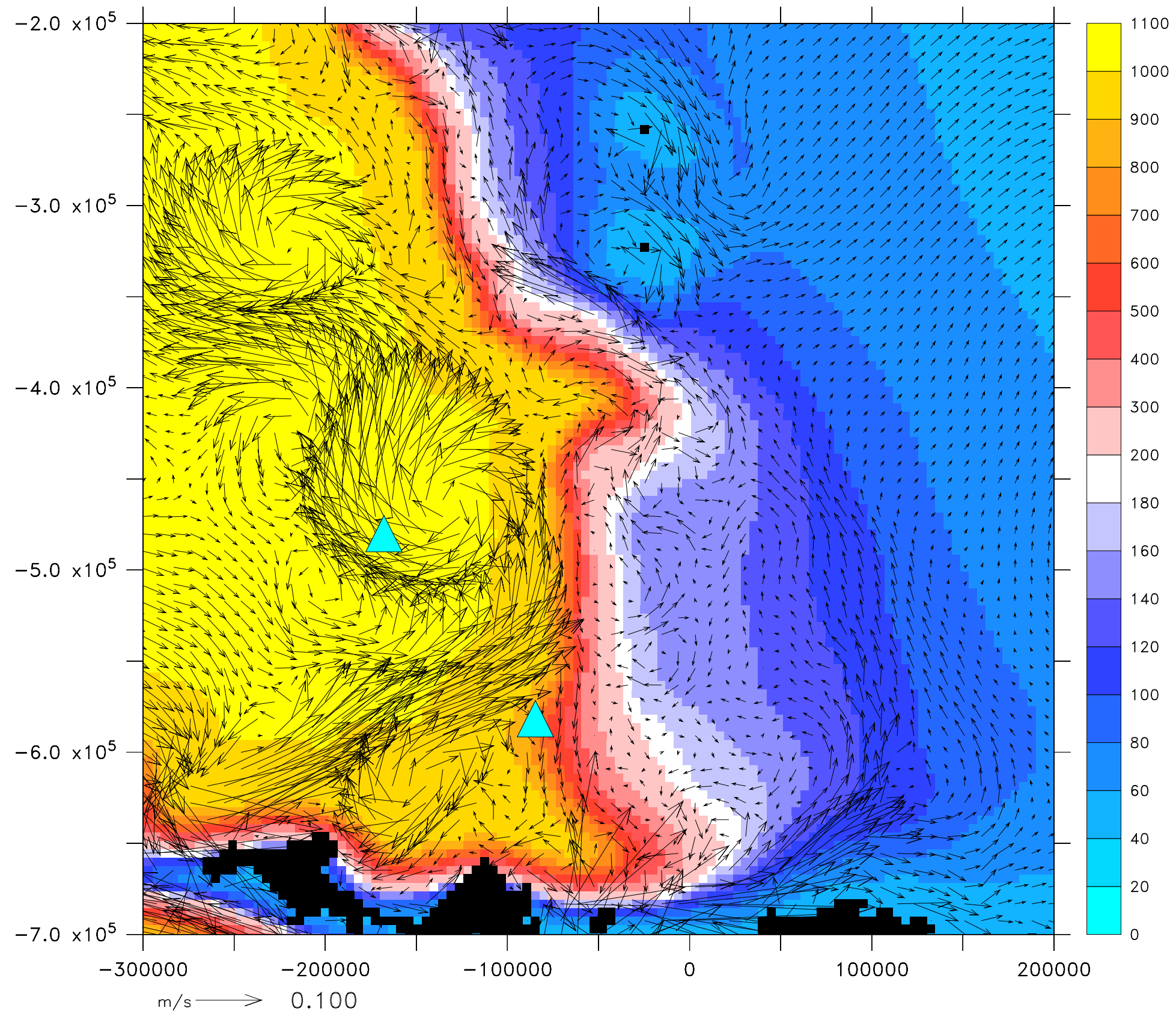

Fig. 5. Same as Fig. 3, for DOY 133.5 (May 13), 1997. Locations of float releases are indicated by triangles. 


\section{VELOCITY IN SEBS DAY $195.51997(7 \mathrm{sV})$}

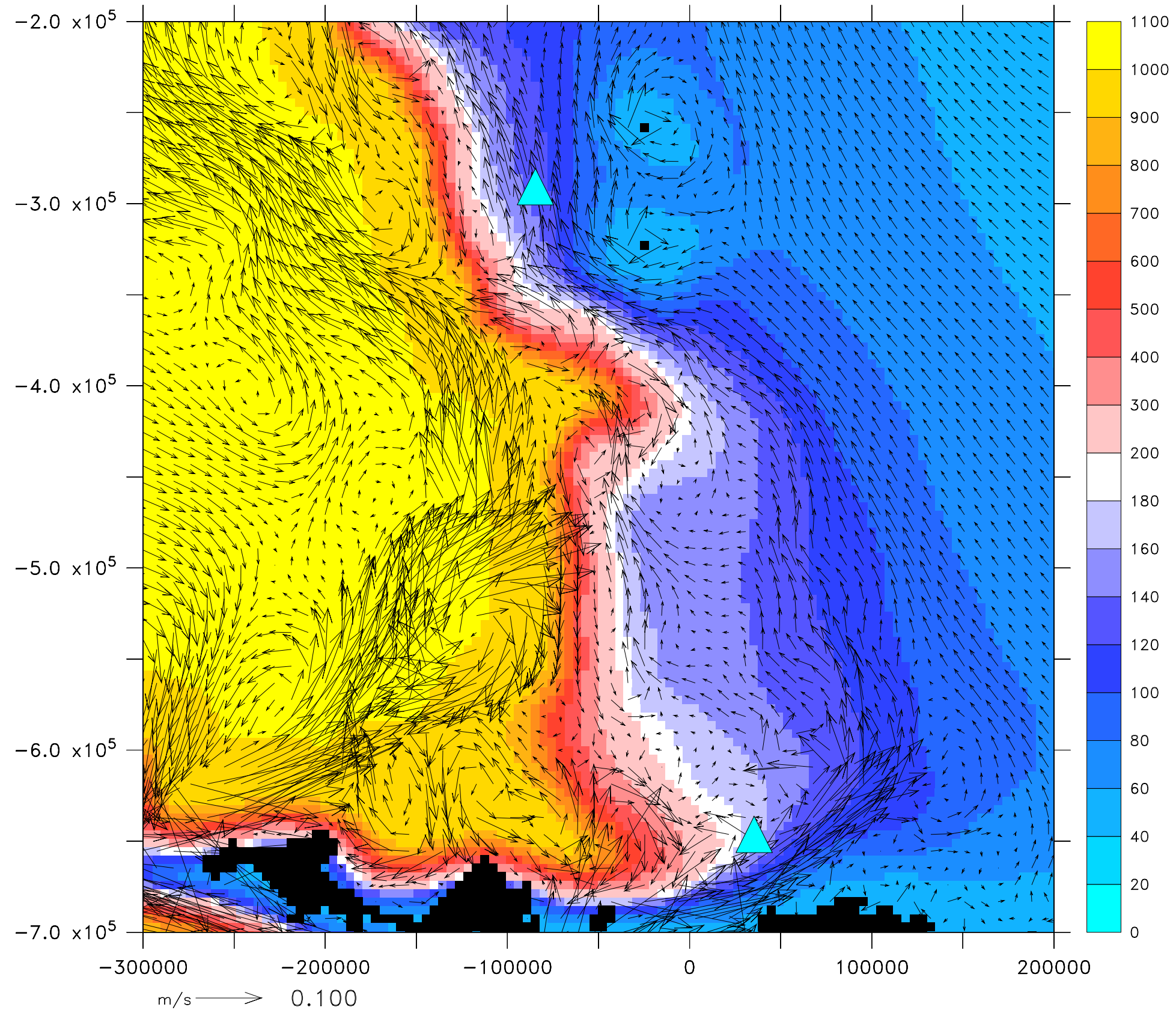

Fig. 6. Same as Fig. 3, for DOY 195.5 (July 14), 1997. Locations of float releases are indicated by triangles. 
Fig. 7. Hovmuller diagrams of depth-integrated alongshelf flow $\left(m^{\wedge} 2 \mathrm{~s}^{\wedge}-1\right)$ at alongshelf distance $y=-5.2 \times 10^{\wedge} 6 \mathrm{~m}$, as a function of cross-basin distance $\left(x=-3 \times 10^{\wedge} 6\right.$ to $-.5 \times 10^{\wedge} 6 \mathrm{~m}$, as in Fig. 3-7) and time (DOY). The shelf break is located at the right-hand edge of the figure $\left(x=-.5 \times 10^{\wedge} 6 \mathrm{~m}\right)$. Results are shown for years $1995(\mathrm{a})$ and $1997(\mathrm{~b})$.

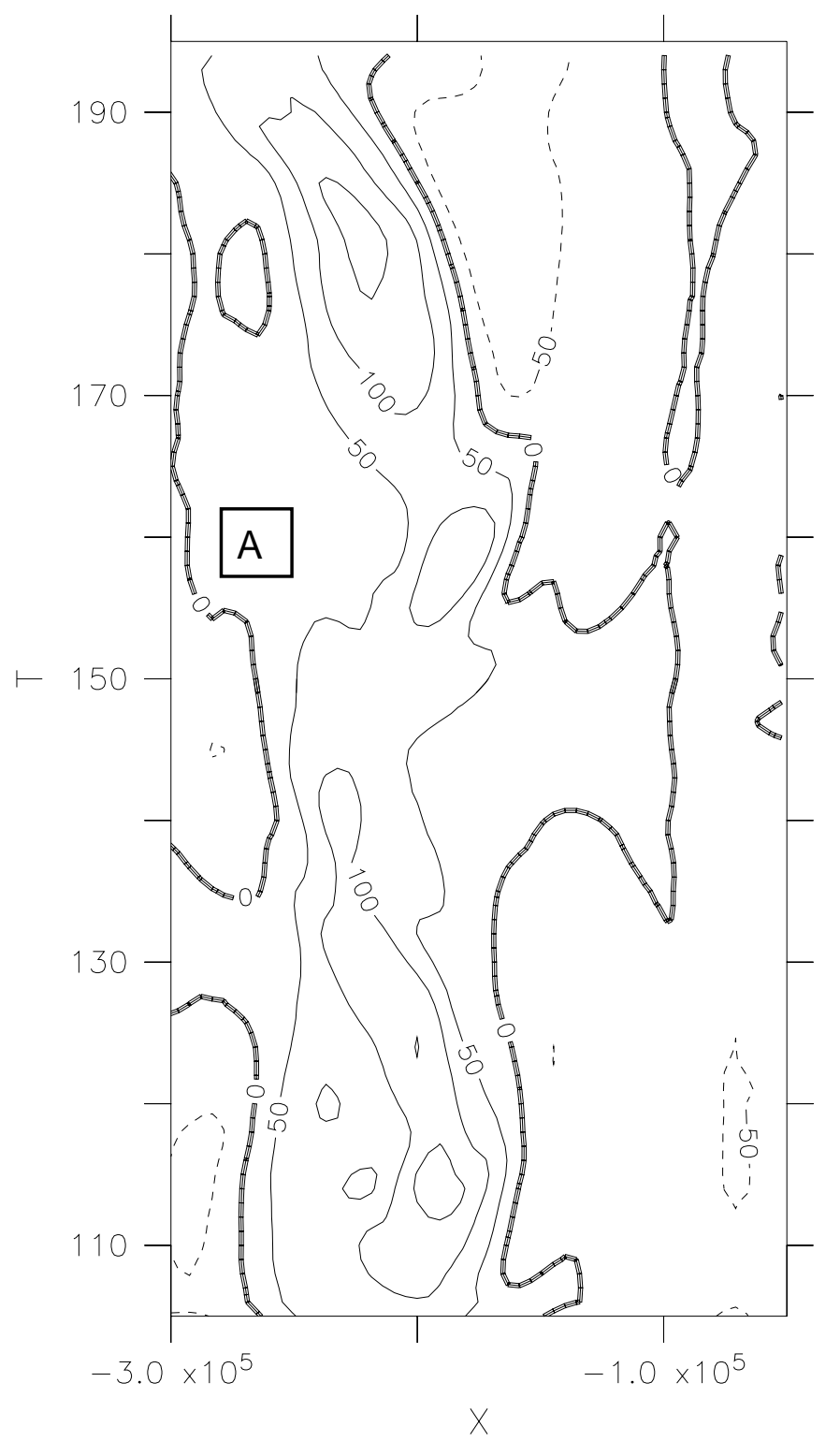

1995
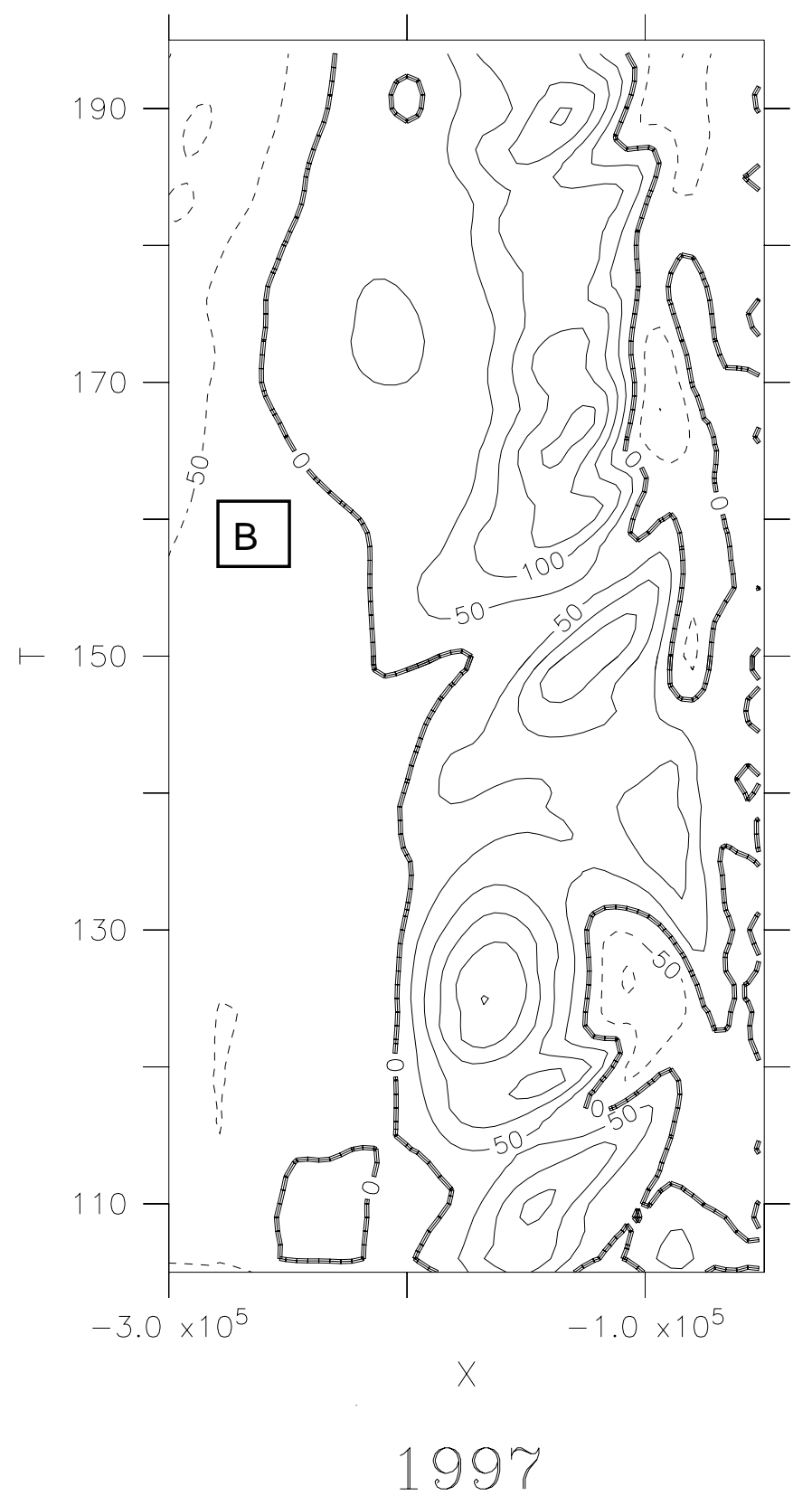


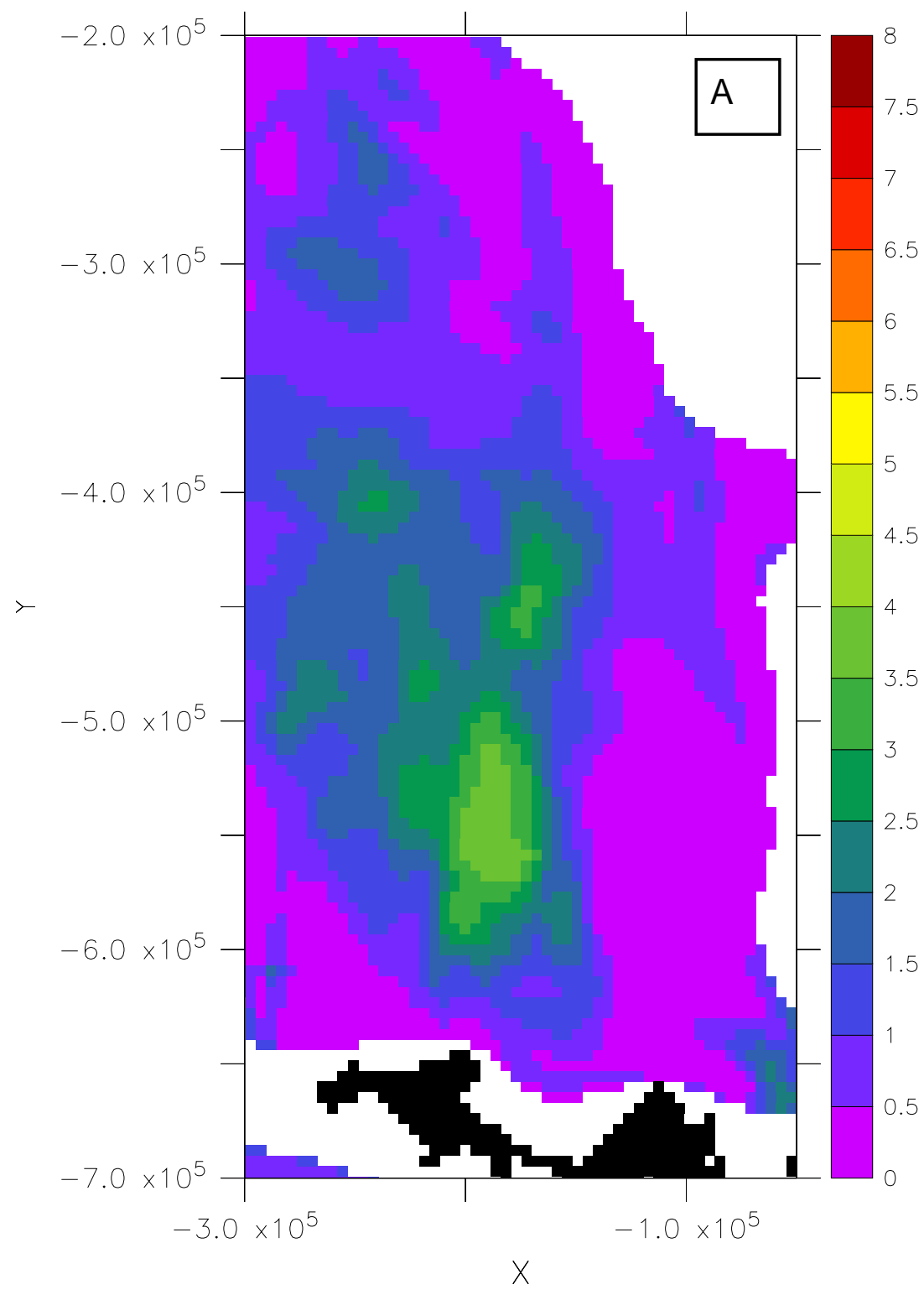

1995

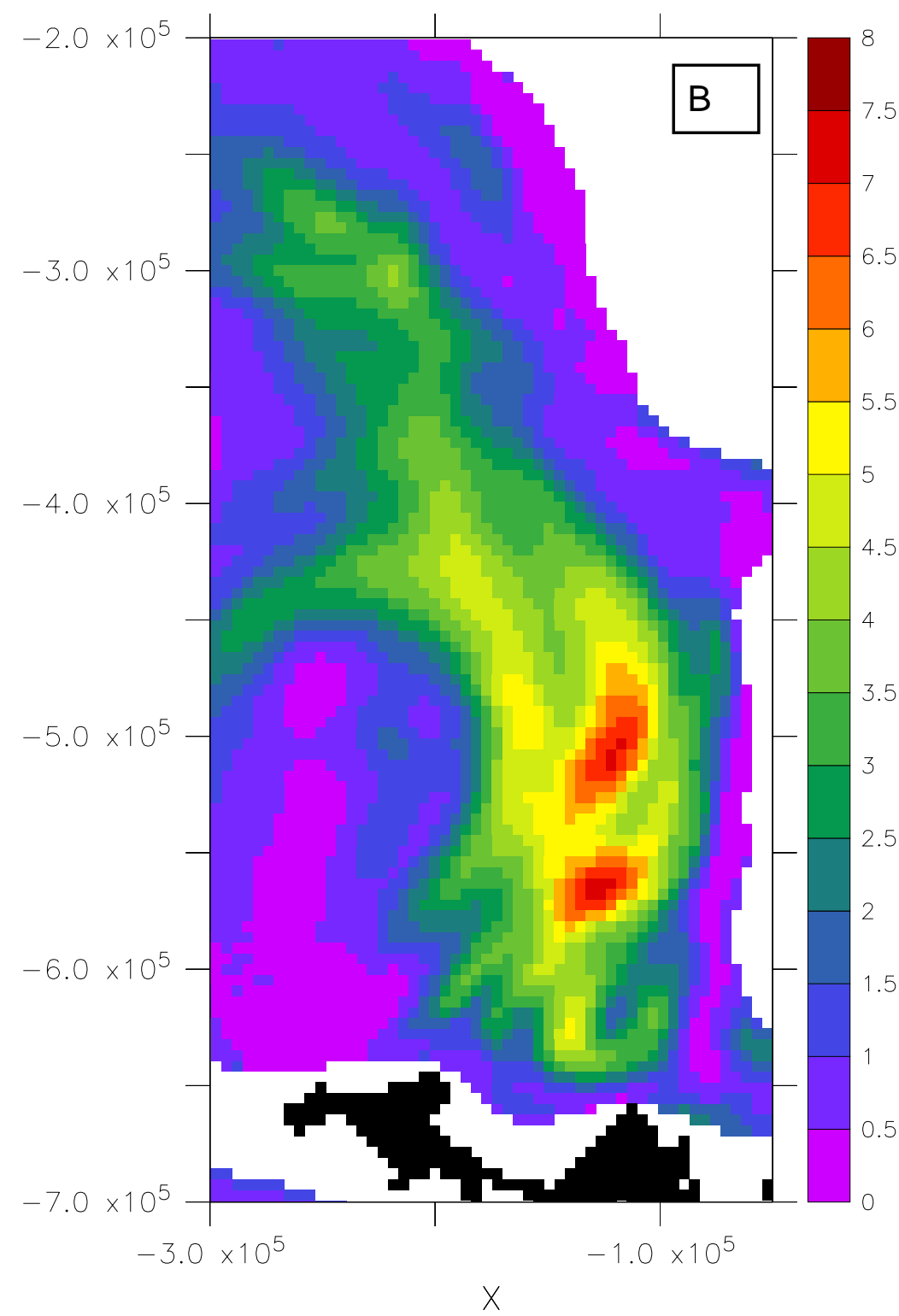

1997 

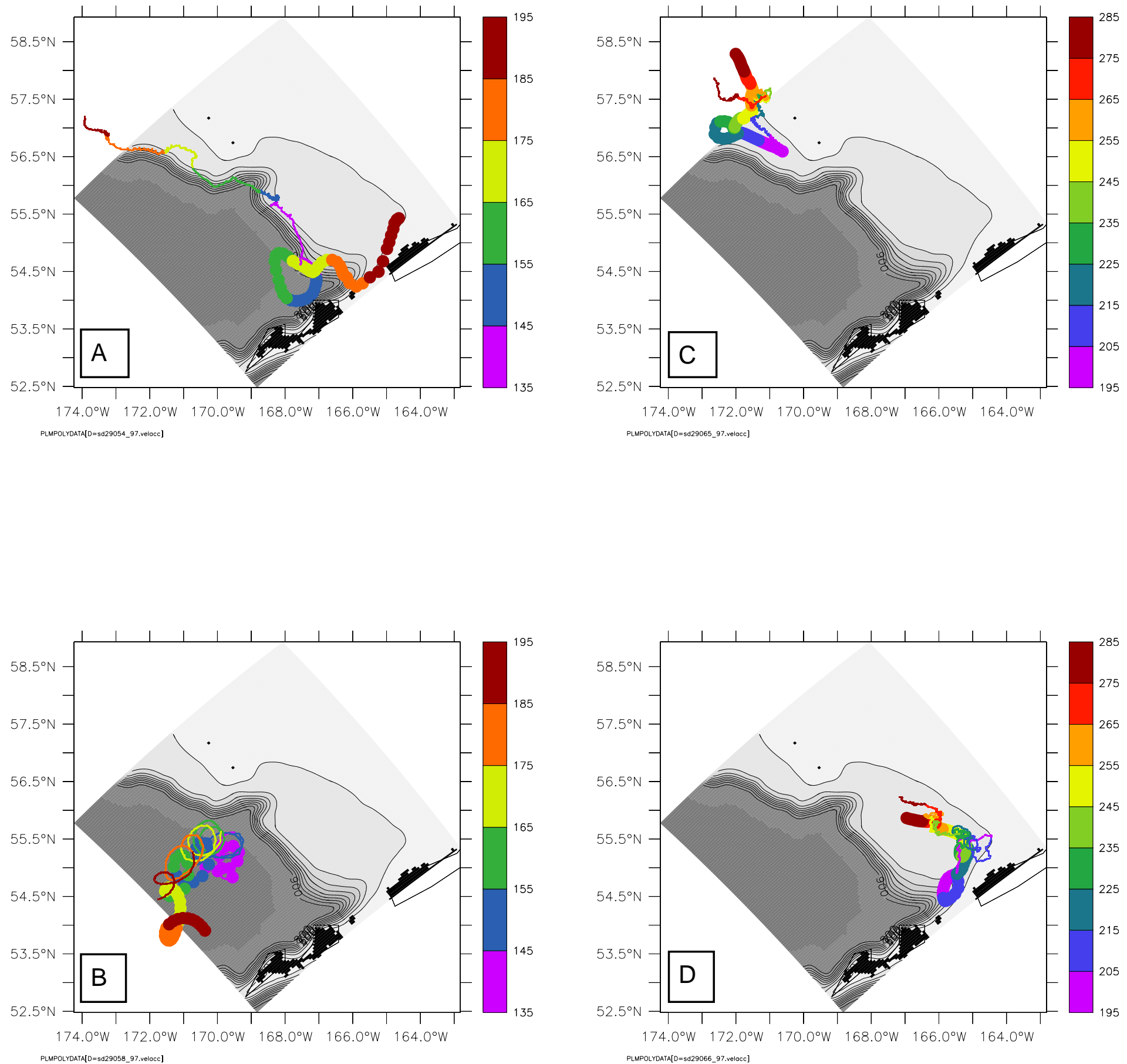

Fig. 9. Actual (thin lines) and simulated (large dots) drifter tracks. Upper left and lower left panels $(a, b)$ represent floats released on DOY 135 (May 15), 1997; upper right and lower right panels (c,d) represent floats released on DOY 195 (Jul 14), 1997. Color indicates DOY (note different colorbars for DOY 135 and 195 tracks). 


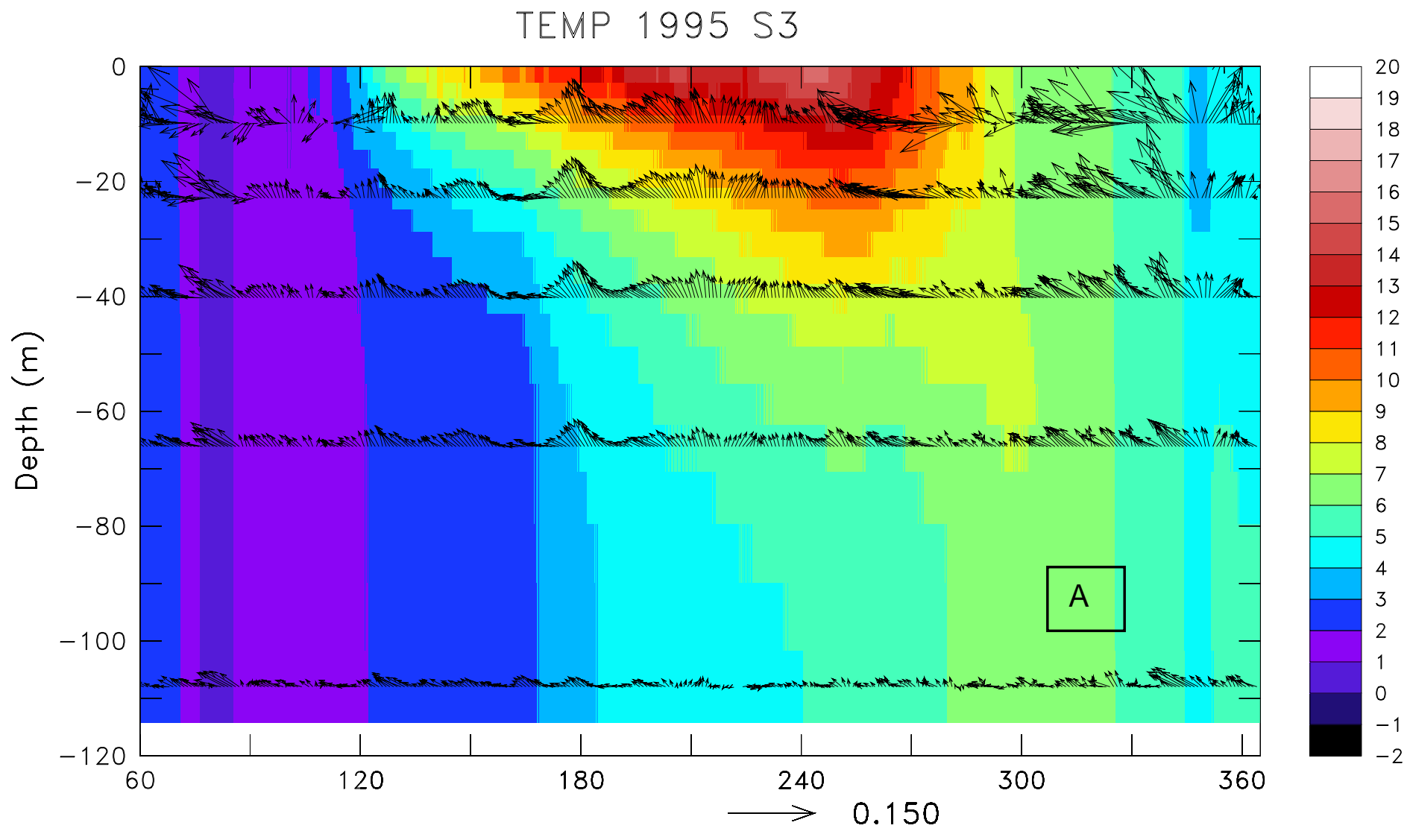

TEMP 1997 S3

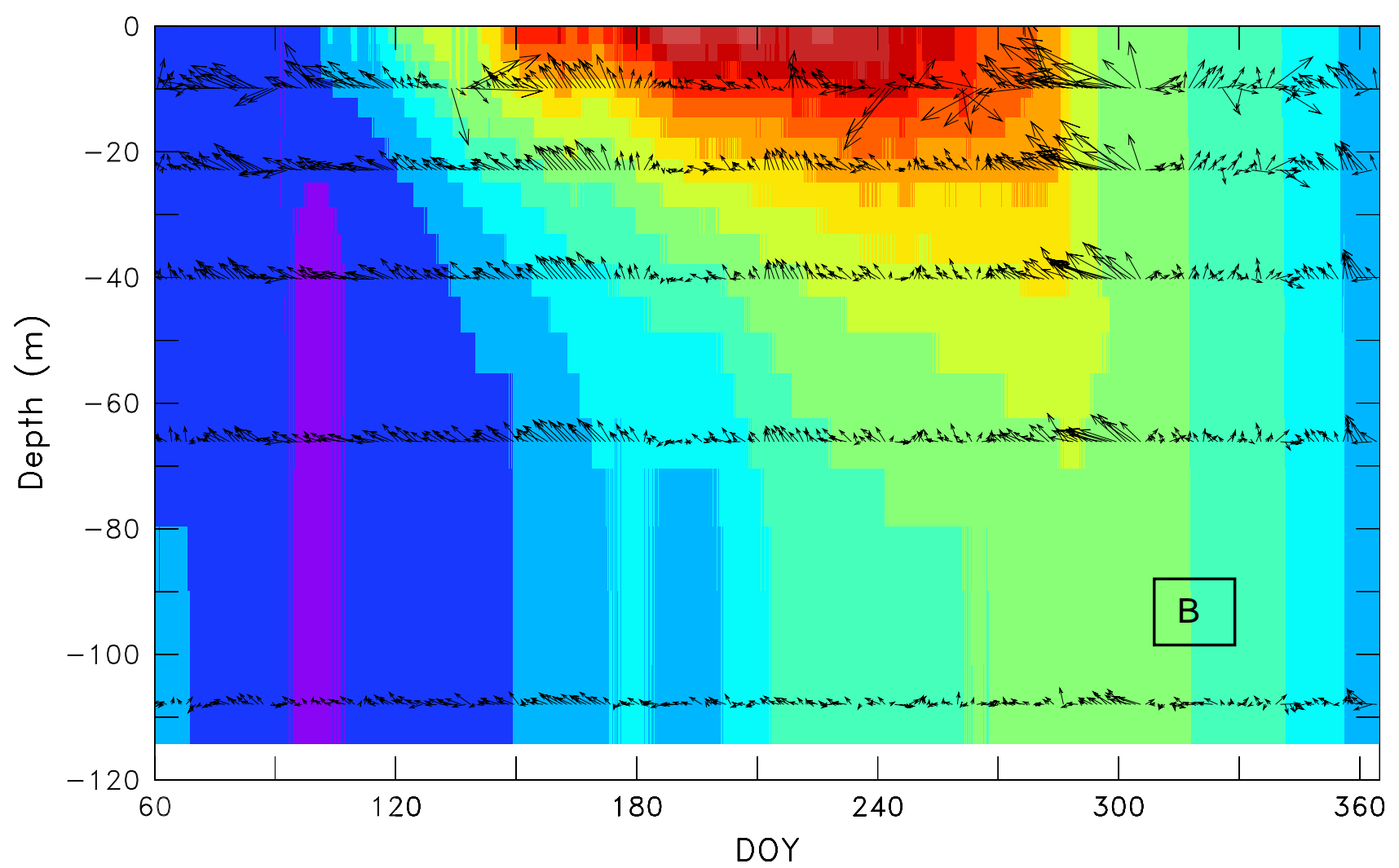

Fig. 10. Time-depth series of modeled temperature $\left({ }^{\circ} \mathrm{C}\right)$ and velocity $\left(\mathrm{m} \mathrm{s}^{-1}\right.$; upward direction indicates northward flow) at mooring site 3 for years 1995 (a) and 1997 (b). 


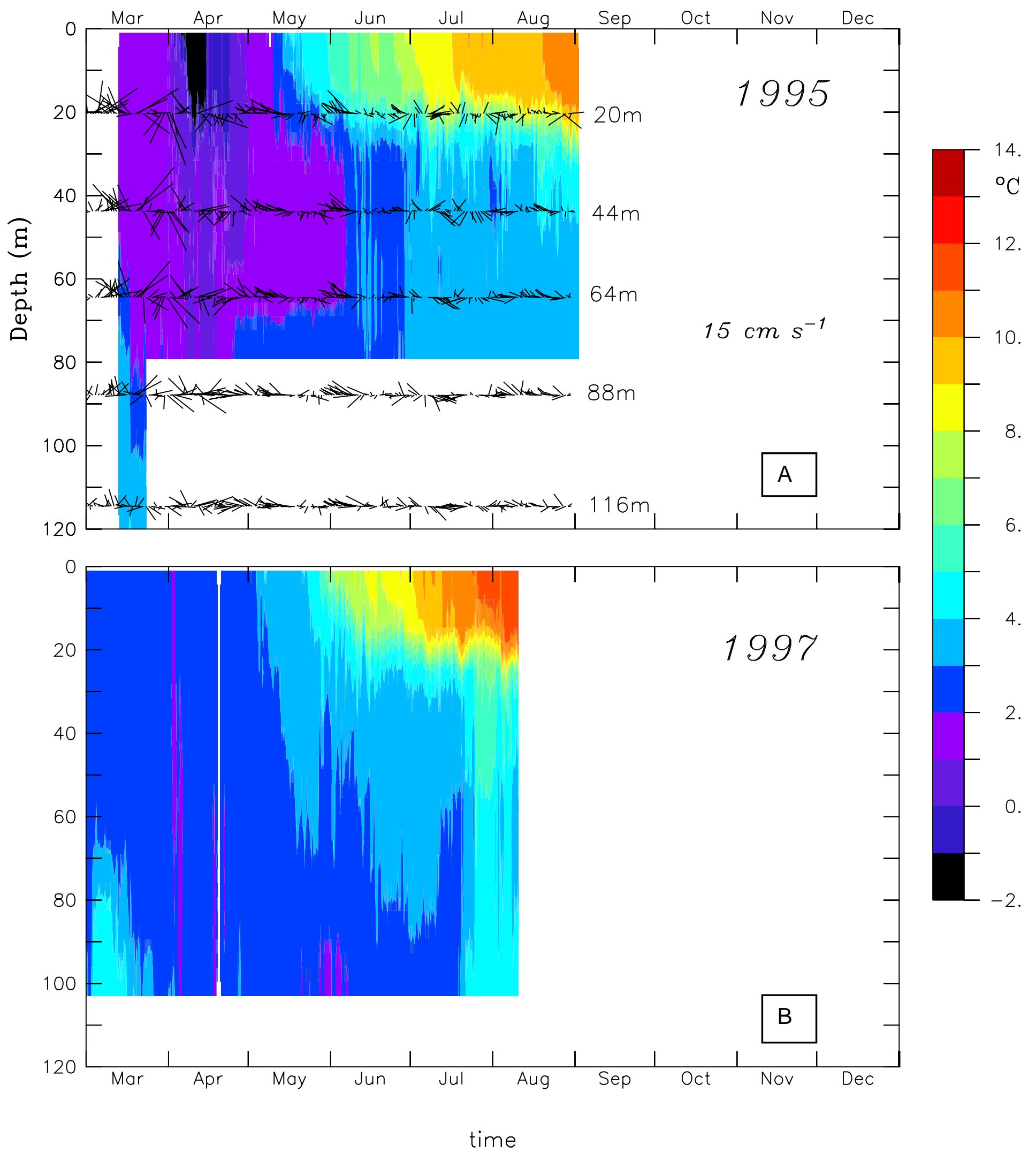

Fig. 11. Time-depth series of measured temperature at mooring site 3 for years 1995 (a) and 1997 (b) 

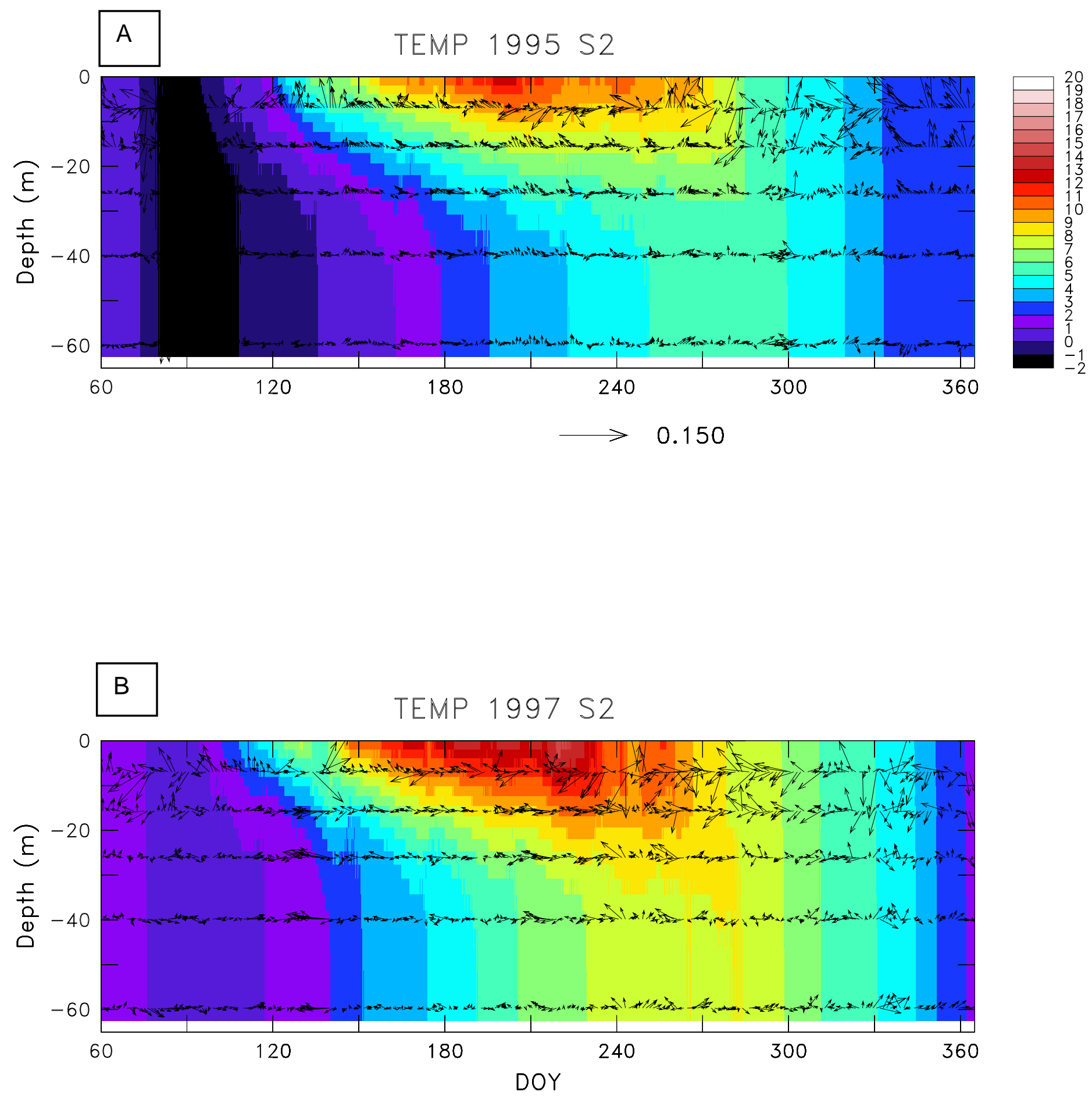

Fig. 12. Time-depth series of modeled temperature at mooring site 2 for years 1995 (a) and 1997 (b). 

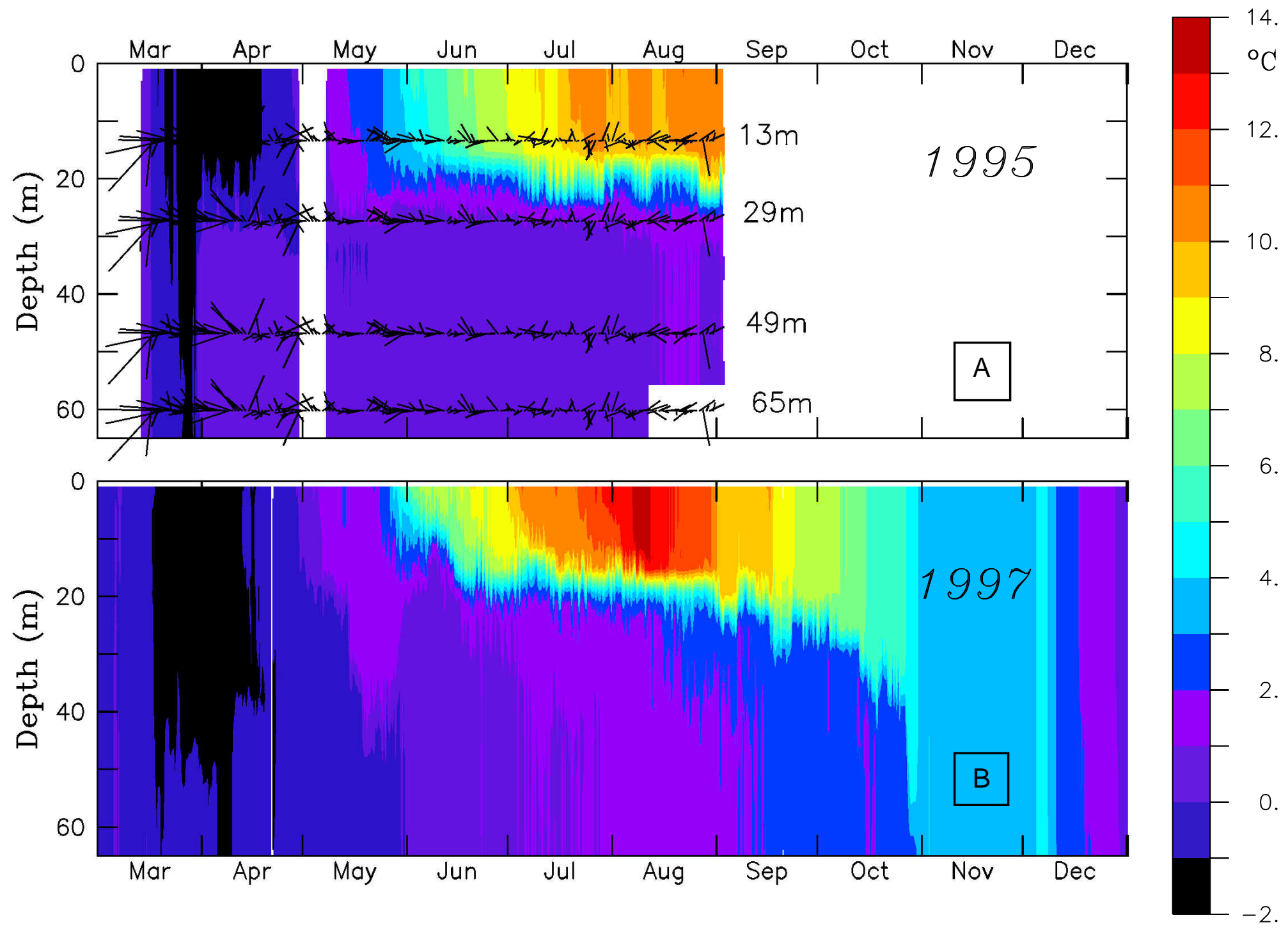

Fig. 13. Time-depth series of measured temperature at mooring site 2 for years 1995 (a) and 1997 (b). 

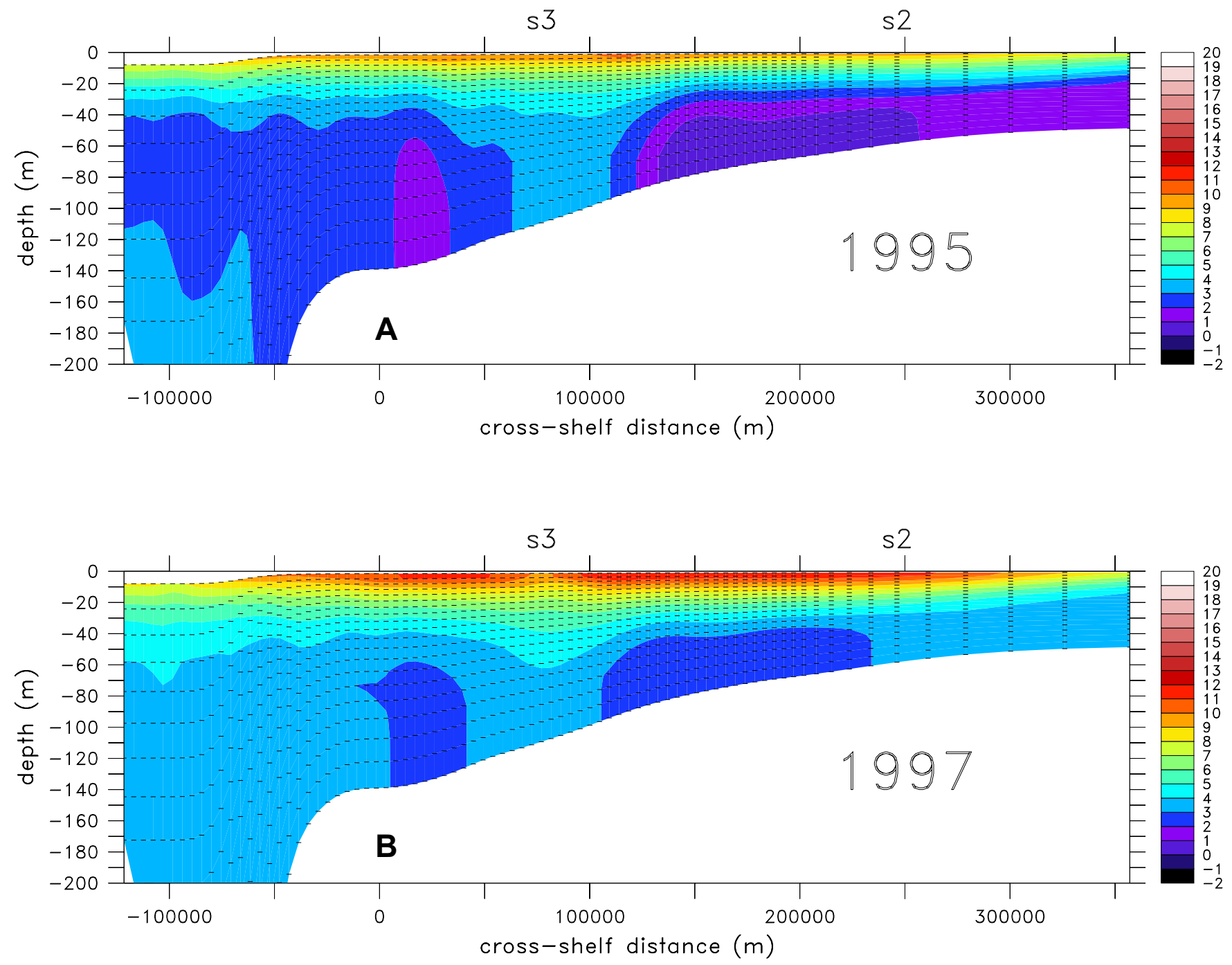

Fig. 14. Cross-shelf transect of modeled temperature ( o C) for mid-June for 1995 (a) and 1997 (b), with approximate locations noted for mooring sites 2 and 3 (see Fig. 1). 


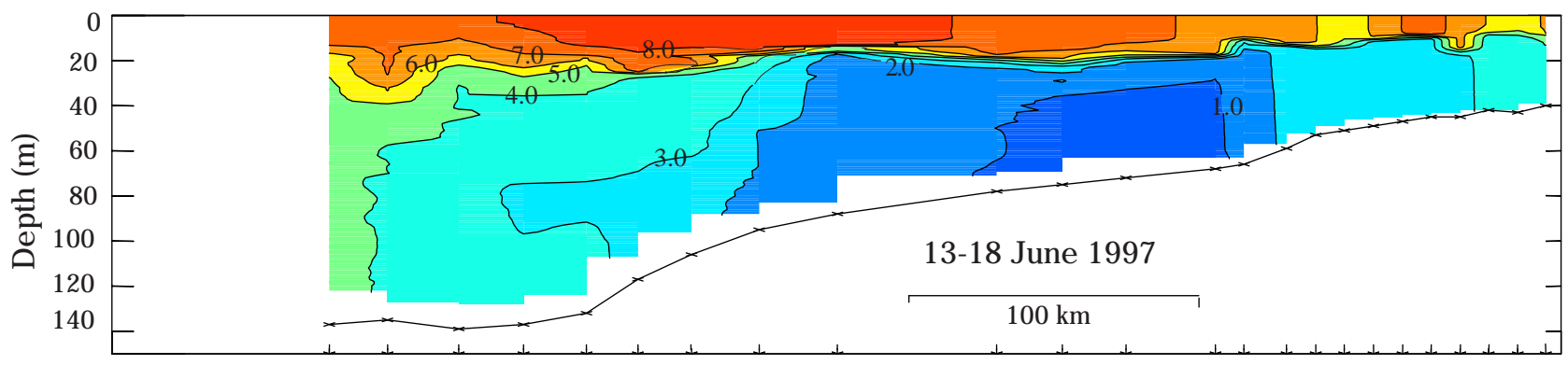

Figure 15. Cross-shelf transect of measured temperature $\left({ }_{o} \mathrm{C}\right.$ ) for mid-June (see Fig. 1 for location). 


\section{MAXIMUM LOG(AKT) IN SEBS DAY $1951997(7 \mathrm{sV})$}

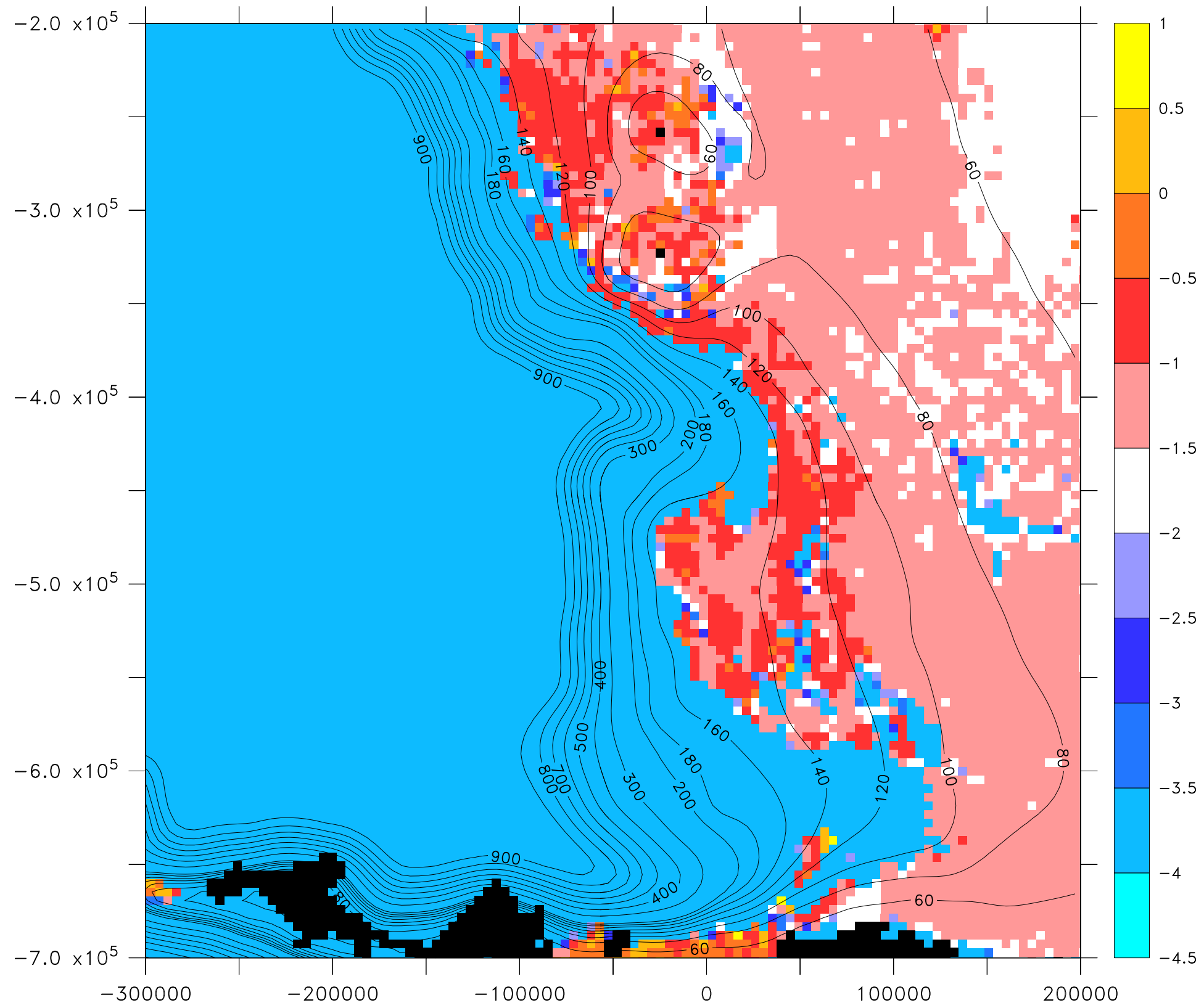

Fig. 16 Log10 of of vertical mixing $\left(\mathrm{m}^{\wedge} 2 \mathrm{~s}^{\wedge}-1\right)$ on DOY 195 (July 14), 1997 as computed by the model. Shaded values represent the maximum value in the water column, as a function of horizontal location. Bathymetry is contoured $(\mathrm{m})$. 